\title{
Der Einfluss von Kohlenwasserstoffen auf die Ökologie der Bakterien im aeroben Seesediment
}

\author{
Von H. Bührer \\ Institut für Gewässerschutz und Wassertechnologie an der Eidgenössischen Technischen Hochschule, \\ Zürich $\left.{ }^{1}\right)$
}

Manuskript eingegangen am 2. Mai 1979

\begin{abstract}
Influence of hydrocarbons on ecology of bacteria in aerobic lake sediment

Two different hydrocarbon loadings of sediment cores were analyzed 4 times during 21 days. Applied methods were: Direct count, isolation of more than 100 colonies on a diluted plate-count agar and estimation of 42 attributes ( 282 levels), followed by a single link clustering and calculation of the information basing on attribute level (i.e. negative entropy). Loading of $100 \mathrm{~g}$ fuel $\mathrm{oil} / \mathrm{m}^{2}$. sediment caused a depletion of germs and information. Full restoration could not be observed. When $10 \mathrm{~g}$ fuel $/ \mathrm{m}^{2}$ was applied there was no significant effect, but if algae were supplied too, the effect was similar to using $100 \mathrm{~g} / \mathrm{m}^{2}$. An extrapolation of the results gives a tolerance of hydrocarbon loading for Lake Constance or Lake Zug of 10 to 20 times the load present, but effects on fishes or fishfood were not considered.
\end{abstract}

\section{Einleitung}

Der wichtigste Parameter für die Beschreibung eines Ökosystems ist die Art bzw. die biologische Spezies. Sie wird gleichzeitig als niedrigste Informationseinheit in der Biologie gewertet; auf dieser Wertung beruht z. B. die Diversitätsformel von Margalef [27], welche der bekannten Binärinformationsformel von Shannon [36] und von Wiener entspricht. Bei dieser Art der Anwendung der Spezies wird freilich vernachlässigt oder übersehen, dass auch die trophische Stufe einen Informationswert besitzt, ferner (in vermindertem Masse) akzessorische Spezies. Auf der andern Seite entspricht Information der Entropie des Systems. Nach dem zweiten Hauptsatz der Thermodynamik ist die höchste Entropie eines Systems bei dessen stabilstem Zustand erreicht. Dieser Hauptsatz ist nun aber nicht auf die chemische Welt beschränkt; ihm unterliegen auch die Organismen. Folgerichtig werden sich daher auch ganze Ökosysteme in dieser Weise verhalten. Im offenen System wird die Entropieproduktion durch die Biozönose minimiert.

Gesamthaft, unter Berücksichtigung der biologischen und thermodynamischen

1) Die Arbeit wurde an der Eidgenössischen Anstalt für Wasserversorgung, Abwasserreinigung und Gewässerschutz (EAWAG) in Dübendorf ausgeführt. Kurzfassung ETH Diss. Nr.6121. 
Kriterien, kann die Stabilität eines Ökosystems folgendermassen definiert werden: Stabil ist ein Ökosystem dann, wenn es sich unter äusseren Belastungen nicht oder kaum verändert. Dabei kann auch die Reversibilität eines Effekts als Kriterium betrachtet werden $[17,20]$.

\section{Problemstellung}

In der vorliegenden Arbeit wurde die Auswirkung einer externen Belastung auf ein eingespieltes ökologisches System experimentell untersucht. Als System wurde die Bakterienflora in ungestörtem Seesediment gewählt, als Belastungsparameter Heizöl «extra leicht». Die Wechselwirkungen des Komplexes Wasser-MineralölMikroorganismen waren seit der Jahrhundertwende immer wieder Gegenstand von Untersuchungen; die Resultate einiger hundert Originalarbeiten sind in Sammelpublikationen von Zobell [50], Fuhs [13], Schöberl [34, 35], Beerstecher [3], Davis [8] und Davis [9] zusammengefasst.

Die verheerenden Folgen von ausgelaufenem Erdöl im Meereslitoral sind bekannt. Auch in den Binnengewässern ereignen sich immer wieder Ölunfälle, über deren Auswirkungen, z. B. auf die Bakterien des Sediments, wenig Klarheit herrscht. Eine Abklärung der damit verbundenen Fragen schien in mehrfacher Hinsicht lohnend. Wenn sich an einem Seezufluss ein Ölunfall ereignet, geschieht folgendes: Ein Teil des Öls wird von sedimentierenden Schwebstoffen adsorptiv gebunden und wandert zum Sediment [14, 41, 42]. Dort wird wegen der verminderten Turbulenz ein Teil des Öls wieder freigesetzt und steigt zur Oberfläche auf, wo es sich als dünner Film ausbreitet. Algen und biogen gebildeter mikrokristalliner Kalk adsorbieren im Epilimnion wieder einen Teil und sinken damit auf den Grund.

Von der Bakterienbiozönose des Sediments her gesehen, gibt es drei unterscheidbare Möglichkeiten:

1. Da die sedimentierte Algenbiomasse besser abbaubar ist als das Heizöl und die gesamte Bakterienbiozönose ohnehin auf Algenabbau spezialisiert ist, wird das Heizöl unverändert gelassen und verschwindet ohne Effekt im lipophilen Sedimentanteil. Diese Möglichkeit ist für anoxische Verhältnisse wahrscheinlicher als für aerobe (siehe S.338, vgl. auch [23]).

2. Das Öl vergiftet die Bakterienpopulation bis auf jene Spezialisten, welche Öl verwerten können. In diesem Fall stünde diesen Bakterien der gesamte Sauerstoffvorrat der sedimentnahen Wasserschicht zur Verfügung.

3. Das Öl und die Algen werden gleichzeitig abgebaut, wobei aber gewisse Bestandteile des Öls persistieren.

Da alle drei Möglichkeiten plausibel sind, muss im Experiment abgeklärt werden, welche zutrifft.

Vorversuche zeigten, dass es möglich ist, die Information, welche die verschiedenen Organismen liefern, zu normieren, um später eine «Informationssumme» berechnen zu können. Gleichzeitig tauchte die Hoffnung auf, dass sich auf diese Weise auch die negative Entropie berechnen lässt. Um die Bakterien und ihre Ökologie als Informationsquelle benützen zu können, müssen sie beschrieben werden, wozu 
verschiedene Methoden verwendet werden können. Am bekanntesten ist die Unterteilung in physiologische Gruppen [22].

Eine grundsätzlich andere Methodik wurde von Lighthart [25] verwendet, nämlich die Charakterisierung der Bakterienbiozönose mit Hilfe der numerischen Taxonomie. Einführende Arbeiten finden sich bei Sokal und Sneath [37] oder Jardine und Sibson [19] und Lockhart et al. [26]. In der vorliegenden Arbeit wurde dieses Verfahren gewählt.

\section{Methoden}

\subsection{Probenahme im See}

Mit dem Bohrlot nach Ambühl und Bührer [1] wurden an der Untersuchungsstelle "Horwer Bucht» (Vierwaldstättersee $8^{\circ} 19^{\prime} 1^{\prime \prime} \mathrm{E}, 47^{\circ} 0^{\prime} 18^{\prime \prime} \mathrm{N}$ ) aus $60 \mathrm{~m}$ Tiefe Sedimentproben entnommen. Die Kerne hatten eine Länge von etwa $40 \mathrm{~cm}$ mit einer Querschnittfläche von $100 \mathrm{~cm}^{2}$ und wurden nach dem Transport im Kühlschrank bei $4^{\circ} \mathrm{C}$ aufbewahrt. Die oberste Schicht der ungestörten Kerne war etwa $10 \mathrm{~mm}$ tief oxydiert. Die Oberfläche bestand aus einer etwa $0,5 \mathrm{~mm}$ dicken verfilzten, bereits etwas abgebauten Algenschicht.

\subsection{Versuchsablauf}

Damit die Entwicklung der Bakterien im Laborexperiment verfolgt werden kann, ist mindestens eine Probenahme pro Woche erforderlich (vgl.4.1). Für die Bestimmung der Kolonien konnten nicht alle jeweils notwendigen Merkmale geprüft werden, da dies zu viel Zeit beansprucht hätte. Aus dem Bestimmungsschlüssel von Bergey [6] und der Anleitung von Lockhart [26] wurde eine Anzahl von Merkmalen so ausgewählt, dass sie bei kleinstmöglichem Arbeitsaufwand möglichst viel Aussagen erlaubten. Als Mindestmass wurde eine Kolonienzahl von 100 festgesetzt. Es zeigte sich, dass es trotz diesen Erleichterungen ohne optimalen Einsatz der Methoden unmöglich war, alle Forderungen des Arbeitsablaufs zu erfüllen. Deshalb wurden alle Arbeitsphasen einzeln gemessen und mit Hilfe der Netzplantechnik schliesslich zu einem durchführbaren Arbeitsablauf zusammengestellt (vgl. Abb. 1).

\subsection{Bakteriologische Methodik}

\subsection{Nährböden}

- Standardnährboden:

Trypton-Glucose-Extract-Agar: 24 g DIFCO, Art.-Nr.0002,

Bacto Agar: 15 g DIFCO, Art.-Nr. 0140,

destilliertes Wasser bis $2000 \mathrm{ml}$.

Damit die Selektivität vermindert werden kann, hat dieser Nährboden die halbe Konzentration der Originalvorschrift (mündl. Mitt. Wuhrmann, 1974).

- Anaerobieragar nach Brewer [29]; Merck, Art.-Nr. 5452.

- Eisen-Zweizucker-Agar nach Kligler [29]; Merck, Art.-Nr. 3913.

- Stärkeagar nach Pochon [33]. 


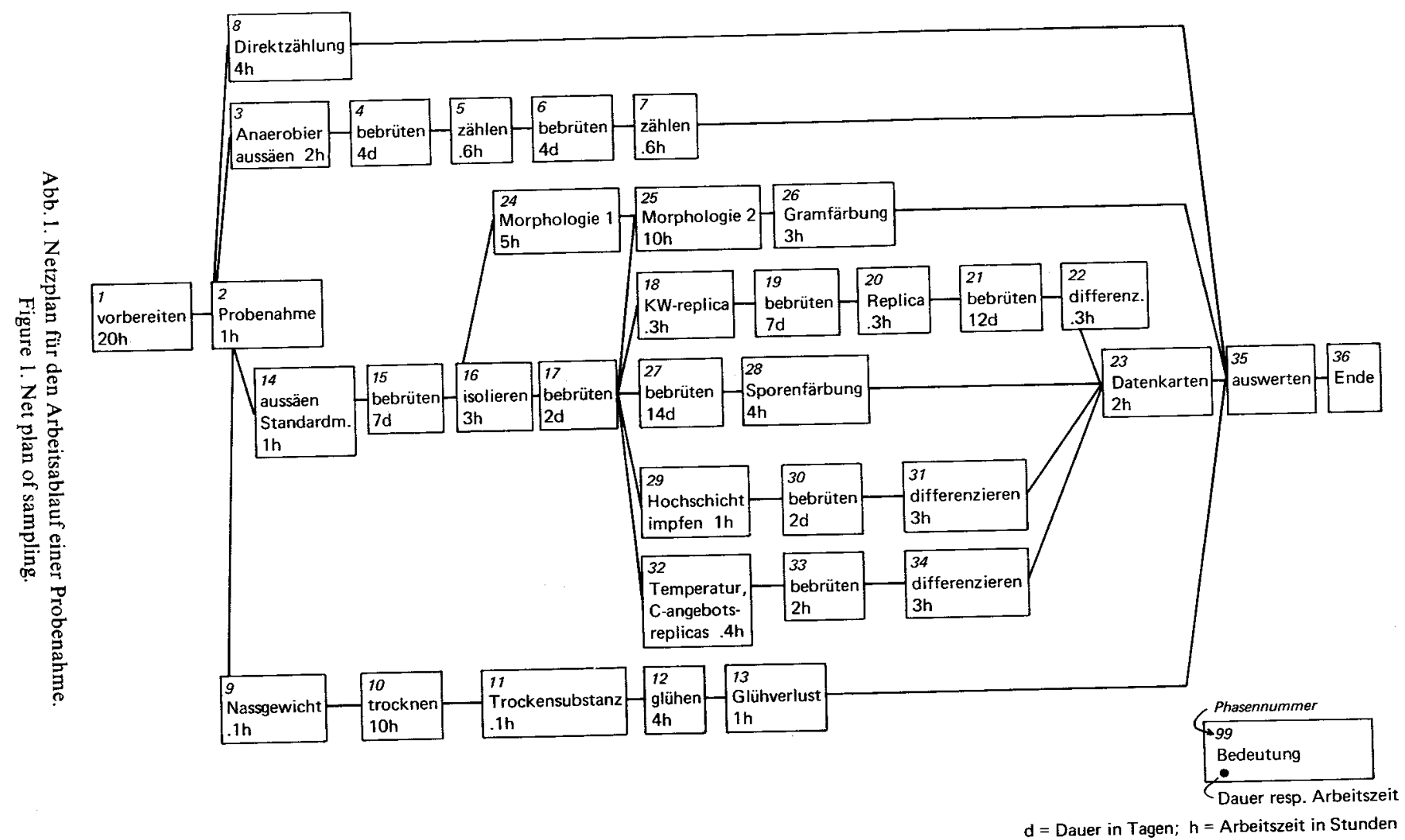


- Kohlenwasserstoffagar: Das Mineralölmedium von Hirsch [16] wurde nach den Angaben von Fuhs [13] modifiziert. Die Spurenelemente liegen in den von Fuhs angegebenen Optima. Im übrigen wurde der Salzgehalt so gering wie möglich gehalten. Für die genaue Formulierung dieses Mediums und den Vergleich mit publizierten Formulierungen siehe Tabelle 2.

- Gelatineagar nach Pelczar [31] (Standardnährboden+4 g Gelatine/1): Differenzieren mit salzsaurem Quecksilberchlorid.

Tabelle 1. Einige Medien für Kohlenwasserstoffoxydanten.

Table 1 . Some media for hydrocarbon oxidizing bacteria.

\begin{tabular}{|c|c|c|c|c|c|}
\hline Substanzen & $\begin{array}{l}\text { Diese } \\
\text { Arbeit } \\
(\mathrm{g}) \\
\end{array}$ & $\begin{array}{l}\text { Schöberl } \\
{[34]} \\
(\mathrm{g})\end{array}$ & $\begin{array}{l}\text { Hirsch } \\
{[16]} \\
(\mathrm{g}) \\
\end{array}$ & $\begin{array}{l}\text { Gunkel } \\
{[15]} \\
\text { (g) }\end{array}$ & $\begin{array}{l}\text { Vorošilova } \\
{[45]} \\
(\mathrm{g})\end{array}$ \\
\hline $\mathrm{NH}_{4} \mathrm{NO}_{3}$ & - & 0,5 & - & - & 1 \\
\hline $\mathrm{NH}_{4} \mathrm{Cl}$ & - & - & - & 0,5 & - \\
\hline $\mathrm{K}_{2} \mathrm{HPO}_{4}$ & 0,5 & 3 & 1 & 0,5 & 1 \\
\hline $\mathrm{KH}_{2} \mathrm{PO}_{4}$ & 0,5 & - & - & - & 1 \\
\hline $\mathrm{Na}_{2} \mathrm{HPO}_{4}$ & - & - & - & 1 & - \\
\hline $\mathrm{NaNO}_{3}$ & 1 & - & 2 & - & - \\
\hline $\mathrm{MgSO}_{4} \cdot 7 \mathrm{H}_{2} \mathrm{O}$ & 0,25 & 0,5 & 0,5 & + & 0,2 \\
\hline $\mathrm{CaCl}_{2} \cdot 4 \mathrm{H}_{2} \mathrm{O}$ & 0,1 & - & 0,15 & + & 0,2 \\
\hline $\mathrm{FeCl}_{3}$ & 0,05 & $\begin{array}{l}\text { Spur } \\
\text { EDTA-Fe }\end{array}$ & 0,01 & + & 0,02 \\
\hline $\mathrm{MnSO}_{4}$ & + & - & 0,0032 & + & + \\
\hline $\begin{array}{l}\mathrm{Cu}, \mathrm{Zn}, \mathrm{NiSO}_{4} ; \mathrm{MoO}_{3} \\
\text { und } \mathrm{Co}\left(\mathrm{NO}_{3}\right)_{2}\end{array}$ & + & - & - & + & + \\
\hline $\mathrm{NH}_{4} \mathrm{VO}_{3}$ & + & 0,001 & - & + & + \\
\hline Öl 1 Tropfen & $\begin{array}{l}\text { adsorpt. } \\
\text { gebunden }\end{array}$ & flüssig & $\begin{array}{l}\text { flüssig } \\
\text { oder daneben }\end{array}$ & flüssig & flüssig \\
\hline Agar & 18 & - & 18 & - & - \\
\hline $\mathrm{H}_{2} \mathrm{O}$ dest. & 1000 & - & 1000 & 250 & - \\
\hline $\mathrm{H}_{2} \mathrm{O}$ bidest. & - & 1000 & - & - & - \\
\hline Aqua font. & - & - & - & - & 1000 \\
\hline Meerwasser, gealtert & - & - & - & 750 & - \\
\hline
\end{tabular}

$+=$ vorhanden.

\subsection{Probenahme aus dem Sedimentkern (Phase Nr. 2 im Netzplan Abb. 1)}

Mit einer langen Pipette wurden aus den obersten $3 \mathrm{~mm}$ dẹs Sediments zwei Proben genommen. Diese wurden mit einem modifizierten Reiber der Firma Bellco (Nr. 1979) vorsichtig von Hand homogenisiert. Von dieser Suspension wurde eine Verdünnungsreihe hergestellt und diese in Hochschichtanaerobierröhrchen (Phase 3) und in Standardplatten (Phase 14) geimpft (Impfung der Standardplatten mit Gusstechnik bei $40^{\circ} \mathrm{C}$ ). Ein Teil der Suspension wurde für die Direktzählung (Phase 8) abgezweigt. Der grosse Rest diente der Bestimmung der gravimetrischen Daten (Phasen 9 bis 13).

- Isolierung der Keime und Impfung der Replica-Stempelplatte (Phase 16, siehe auch Phasen 18 und 32): Die Auswahl der Keime erfolgte auf einer Standardplatte mit ungefähr 100 Kolonien. 


\subsection{Morphologie (Phasen 24 und 25)}

Die Auswahl und Auswertung der Morphologiekriterien erfolgte nach Lockhart [26].

- Grösse: Für die Länge wurden 20 Keime mit dem Okularmikrometer ausgemessen und der Mittelwert und die Standardabweichung berechnet.

- Begeisselung: Die Begeisselung wurde im allgemeinen aus dem Bewegungstyp abgeleitet und mikroskopisch im Dunkelfeld (1200fach) bestätigt, sonst Färbung nach Leifson [24]. Auf ein optimales Medium musste verzichtet werden.

- Das Wachstumsbild wurde nach allgemein üblichen Kriterien (Müller und Melchinger [30], Bergey [6]) differenziert, wobei hauptsächlich das Wachstumsbild junger Kolonien berücksichtigt wurde.

- Pigmentierung: Die Pigmentierung wurde in ein Hauptmerkmal (=Farbe) und ein Hilfsmerkmal (= Farbstich der Hauptfarbe) aufgeteilt.

- Gramfärbung (Phase 26) nach BBL-Manual [2]: Färbung mit Huckers Kristallviolett, Differenzieren mit J-NaOH und Äthanol, Gegenfärbung mit Safranin, wobei 24 Stunden alte Kulturen von Escherichia coli und Streptococcus faecalis als Minus- und Plusproben (Zeugen) dienten.

- Sporenfärbung (Phase 28) nach Wirtz [49].

- Koloniegrösse (Phasen 16, 22, 25 und 34): Als Mass für Wachstumsleistungen der Bakterien wurde der Koloniedurchmesser gewählt. Die Grenzen der Durchmesser finden sich in Tabelle 2 unter Eigenschaft 11. Das Verhältnis zwei aufeinanderfolgender Kolonieflächen beträgt 3,05.

\subsection{Direktzählung nach Bührer [7] (Phase 8)}

\subsection{Stichreplicas (Phasen 18 und 32)}

Damit mehrere Kolonien gleichzeitig geimpft werden können, wurde ein Impfstempel hergestellt. Er besteht aus einer eisernen quadratischen Grundplatte von $1,5 \mathrm{~mm}$ Dicke und $80 \mathrm{~mm}$ Seitenlänge, mit 19 auf gleiche Länge geschliffenen, parallelen Impfnadeln aus Wironit (nichtzundernder, harter, als elektrischer Widerstand verwendeter Draht, kann als billiger Ersatz für Pt-Ir verwendet werden).

\subsection{Statistische Zählfehler}

Die statistischen Zählfehler (Standardabweichungen) betragen für die Direktzählung 12\%, für die Gesamtkeimzahl (5 parallele Platten, in Zehnerstufen, gewichtet zusammengezählt) $6 \%$, für die Anaerobierzahl $12 \%$ und für die Gasproduzenten $30 \%$.

\subsection{Liste der Merkmale mit den Codierungen}

Diskrete Eigenschaften wurden mit Buchstaben codiert, während für gleitende Eigenschaften Zahlen verwendet wurden. Die Einzelheiten stehen in Tabelle 2. 
Tabelle 2. Verwendete Merkmale mit ihrer Codierung.

Table 2. Characterizing tests and their codes.

\begin{tabular}{|c|c|c|c|c|c|}
\hline $\mathrm{Nr}$. & Code & Name & Nr. & Code & Name \\
\hline 1 & & Länge & 11 & & $\varnothing \mathrm{Koloniegrösse} \mathrm{in} \mathrm{mm}$ \\
\hline 2 & & Breite 2 Stellen & & 0 & kein Wachstum \\
\hline 3 & & Standardabweichung Länge & & 1 & $<0,3$ \\
\hline \multirow[t]{5}{*}{4} & & Länge, Breite & & 2 & $0,3-0,53$ \\
\hline & 1 & lang 3:1 & & 3 & $0,53-0,92$ \\
\hline & 2 & kurz 2-3:1 & & 4 & $0,92-1,6$ \\
\hline & 3 & oval, rund & & 5 & $1,6-2,9$ \\
\hline & 4 & variabel & & 6 & $2,9-4,9$ \\
\hline \multirow[t]{8}{*}{5} & & Form & & 7 & $4,9-8,6$ \\
\hline & A & gerade & & 8 & $8,6-15$ \\
\hline & B & krumm & & 9 & $>15$ \\
\hline & $\mathrm{C}$ & spiralig & 12 & & Kolonie im Vertikalschnitt \\
\hline & $\mathrm{D}$ & coccoid & & A & flach \\
\hline & $\mathrm{E}$ & Kugel & & $\mathbf{B}$ & flach konvex \\
\hline & $\mathrm{F}$ & ästig & & $\mathrm{C}$ & erhaben \\
\hline & $\mathrm{G}$ & pleomorph & & $\mathrm{D}$ & konvex \\
\hline \multirow[t]{5}{*}{6} & & Ende & & $\mathrm{E}$ & konvex warzenförmig \\
\hline & A & eckig & & $\mathrm{F}$ & konvex gerunzelt \\
\hline & B & rund & & $\mathrm{G}$ & nabelformig \\
\hline & $\mathrm{C}$ & spitz & & $\mathrm{H}$ & knopfförmig \\
\hline & $\mathrm{D}$ & fusiform & & $\mathrm{I}$ & halbkugelig \\
\hline \multirow[t]{3}{*}{7} & & Sporenbildung & 13 & & Kolonierand \\
\hline & A & vorhanden & & A & glatt \\
\hline & B & abwesend & & B & genagt \\
\hline \multirow[t]{6}{*}{. } & $\mathrm{C}$ & endständig & & $\mathrm{C}$ & gekerbt \\
\hline & $\mathrm{D}$ & endständig geschwollen & & $\mathrm{D}$ & wellenförmig \\
\hline & $\mathrm{E}$ & median & & $\mathrm{E}$ & gelappt \\
\hline & $\mathrm{F}$ & median geschwollen & & $\mathrm{F}$ & wimpernförmig \\
\hline & $\mathrm{G}$ & subpolar & & $\mathrm{G}$ & gefranst \\
\hline & $\mathrm{H}$ & subpolar geschwollen & & $\mathrm{H}$ & zerrissen \\
\hline \multirow[t]{4}{*}{8} & & Gramfärbung & & I & verästelt \\
\hline & A & positiv & 14 & & Innere Struktur \\
\hline & B & negativ & & 1 & durchsichtig \\
\hline & $\mathrm{C}$ & variabel & & 2 & durchscheinend \\
\hline \multirow[t]{7}{*}{9} & & Begeisselung & & 3 & opak \\
\hline & A & unbeweglich & 15 & & Oberfläche \\
\hline & B & polar (mono-, lophotrich) & & A & glatt \\
\hline & $\mathrm{C}$ & peritrich & & B & feingranuliert \\
\hline & D & lateral oder gemischt & & $\mathrm{C}$ & grobgranuliert \\
\hline & $\mathrm{E}$ & drehend (Spirochäten) & & $\mathrm{D}$ & lockig-wellig \\
\hline & $\mathrm{F}$ & gleitend (auf Medium) & & $\mathrm{E}$ & fädig \\
\hline \multirow[t]{10}{*}{10} & & Anordnung der Zellen & & $\mathrm{F}$ & baumartig \\
\hline & A & Einzelzellen & 16 & & Pigmente \\
\hline & B & gepaart & & A & farblos \\
\hline & $\mathrm{C}$ & kurze Ketten $<5$ Stück & & B & weiss \\
\hline & $\mathrm{D}$ & lange Ketten $\geqslant 5$ Stück & & $\mathrm{C}$ & gelb \\
\hline & $\mathrm{E}$ & Klumpen von Kokken & & $\mathrm{D}$ & orange \\
\hline & $\mathrm{F}$ & Kokkenpakete (Sarcinen) & & $\mathrm{E}$ & rosa \\
\hline & G & Filamente 1:20 lang & & $\mathrm{F}$ & rot \\
\hline & $\mathrm{H}$ & variabel & & $\mathrm{G}$ & grün \\
\hline & & & & H & violett-purpur \\
\hline
\end{tabular}


Tab.2 (Fortsetzung)

\begin{tabular}{|c|c|c|c|c|c|c|}
\hline Nr. & Code & Name & & Nr. & Code & Name \\
\hline & $\mathbf{K}$ & braun & $\cdot$ & & A & uniform \\
\hline & $\mathrm{L}$ & schwarz & & & B & best at top \\
\hline \multirow[t]{3}{*}{17} & & Pigmente (Tönung der & & & C & best at bottom \\
\hline & & ersten Farbe) & & 34 & & Konsistenz \\
\hline & Codier & ung wie 16 & & & A & butterig \\
\hline \multirow[t]{6}{*}{18} & & Diffundierende Farbstoffe & & & B & viskös (zieht Fäden) \\
\hline & $\mathbf{A}$ & nichts oder farblos & & & $\mathrm{C}$ & membranartig dünn \\
\hline & B & gelb & & & $\mathrm{D}$ & fragil, zerbrechlich \\
\hline & $\mathrm{C}$ & grün & & 35 & & Geruch \\
\hline & D & braun & & & A & abwesend (Fleischbrühe) \\
\hline & $\mathrm{E}$ & schwarz & & & B & vorhanden, schwach \\
\hline \multirow[t]{2}{*}{19} & & Gelatinekoloniegrösse & & & $\mathrm{E}$ & wie E.coli \\
\hline & Codie & ung wie Nr. 11 & & & $\mathbf{F}$ & pilzig \\
\hline \multirow[t]{5}{*}{20} & & Oberfläche Gelatinekolonie & & & $\mathbf{K}$ & komisch \\
\hline & A & glatt & & & $\mathbf{M}$ & moderig, muffig \\
\hline & B & Relief & & & $\mathbf{P}$ & pseudomonadig \\
\hline & $\mathrm{C}$ & gerunzelt & & & $\mathbf{S}$ & stinkt stark \\
\hline & D & dünn, fragil & & 36 & & $\mathrm{H}_{2} \mathrm{~S}$-Bildung \\
\hline \multirow[t]{3}{*}{21} & & Gelatineverflüssigung & & & A & negativ \\
\hline & A & negativ & & & B & nur oben \\
\hline & B & positiv & & & $\mathrm{C}$ & uniform \\
\hline \multirow[t]{2}{*}{22} & & Stärkekoloniegrösse & & & $\mathrm{D}$ & nur unten \\
\hline & Codie & ung wie Nr. 11 & & & $\mathrm{E}$ & schmutzig grün \\
\hline \multirow[t]{4}{*}{23} & & Stärkehydrolyse & & 37 & & Laktoseabbau \\
\hline & A & negativ & & & A & negativ \\
\hline & B & rot (Erythrodextrin) & & & B & sauer (gelb) \\
\hline & $\mathrm{C}$ & positiv & & & $\mathrm{C}$ & alkalisch (rot) \\
\hline 24 & & $4^{\circ} \mathrm{C}$ Wachstum wie 11 & & 38 & & Glukoseabbau \\
\hline 25 & & $10^{\circ} \mathrm{C}$ Wachstum wie 11 & & & A & negativ \\
\hline 26 & & $20^{\circ} \mathrm{C}$ Wachstum wie 11 & & & B & sauer \\
\hline 27 & & $28^{\circ} \mathrm{C}$ Wachstum wie 11 & & & C & alkalisch \\
\hline 28 & & $37^{\circ} \mathrm{C}$ Wachstum wie 11 & . & 39 & & Gasbildung \\
\hline 29 & & $44^{\circ} \mathrm{C}$ Wachstum wie 11 & & & A & negativ \\
\hline \multirow[t]{5}{*}{30} & & Strichwachstum & & & $\mathrm{B}$ & positiv \\
\hline & 1 & keines & & 40 & & Heizölkoloniegrösse \\
\hline & 2 & kärglich & & & Codier & rung wie 11 \\
\hline & 3 & mittel & . & 41 & & Scheidenbildung \\
\hline & 4 & viel & & & A & negativ $<0,2 \mu$ \\
\hline \multirow[t]{7}{*}{31} & & Strichform & & & B & positiv $>0,3 \mu$ \\
\hline & A & filiform & & & $\mathrm{C}$ & dick \\
\hline & $\mathrm{B}$ & echinate & & & $\mathrm{D}$ & stalked \\
\hline & $\mathrm{C}$ & beaded & & 42 & & Andere optische Eigenschaften \\
\hline & $\mathrm{D}$ & effuse & & & A & keine \\
\hline & $\mathrm{E}$ & arborescent & & & B & fluoreszierend \\
\hline & $\mathbf{F}$ & rhizoid & & & $\mathrm{C}$ & irisierend \\
\hline \multirow[t]{6}{*}{32} & & Strichform & & & & \\
\hline & A & filiform & & & & \\
\hline & B & beaded & & & & \\
\hline & $\mathrm{C}$ & papilate & & & & \\
\hline & $\mathrm{D}$ & villous & & & $\cdot$ & \\
\hline & $\mathrm{E}$ & arborescent & & & & \\
\hline 33 & & Sauerstoffbedarf & & & & \\
\hline
\end{tabular}



$G$ $\begin{array}{lll}1 & F & \\ B & B & 3 \\ B & B & B\end{array}$

$\begin{array}{llllllllll}1.2 & 0.8 .4 & 2 & B & B & B & B & B \\ B & +\end{array}$

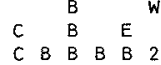

$\begin{array}{lllllll}C & B & B & B & B & 2 \\ A & B & B & B & 1 & A\end{array}$ 1.50 .4 .42 A B B B B 1 1.800 .5 .722 A B B B B 35

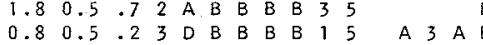
1.50 .52 A B B B B A $A$ A $B$ A

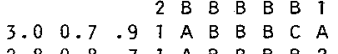
2.80 .8 .7 1 А B. В В B 2

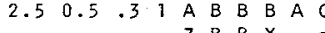

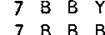

0.90 .9 .1377 В В С В 2 $\begin{array}{llllll}7 & B & B & C & B & 2 \\ 7 & B & B & C & A & 2 \\ 3 & & 2\end{array}$ 3 E B B A A + E B B A A +

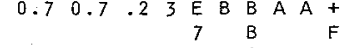

$\begin{array}{lllllll}0.8 & A & B & 8 & Y & Y & 3 \\ 0.8 & A & B & \\ 1.0 & A & B & Y & Y & Y & 3 \\ & A & B & Y & Y & Y & 3\end{array}$

A $B$ S 6 Y $Y 3$

3.00 .8 .92 A

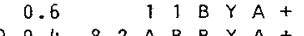
$1.00 .4524 A B B Y A+B A 2 A B+$ 1.0
1.0 0.4 .222 A B B A A C $A$ B $B$ A $A$

$\begin{array}{lllll}B & A & 2 & A & B \\ B & A & 2 & A & A \\ A & & & & B\end{array}$ $\begin{array}{llllllllllllllll}A & A & 3 & 3 & C & D & 3 & A & D & D & A & 3 & A & A & 3 \\ A & A & 3 & 3 & F & A & 3 & A & C & B & A & 3 & A & A & 3\end{array}$

$\begin{array}{lllll}2.0 & 0.3 & .7 & 1\end{array}$ $4.00 .6 .91 \mathrm{G} B$ B $A$ A 3 3 3 F A 3 A C

$1+151042111111111$
1111111

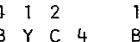

$8 \mathrm{~K}$

$6 \quad 6 \quad A$

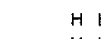

$\mathrm{HH}$

$3 \stackrel{4}{\mathrm{H}}+\mathrm{H}$ 4

B + 3
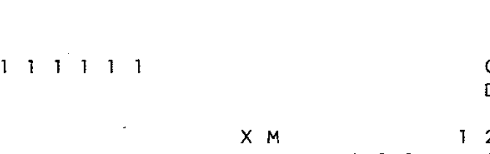
Bergey [6] und sind mit ihren Merkmalen in Tabelle 2 zusammengestellt. Sämtliche aufgeführten Arten oder Standardtaxa kommen im Süsswasser oder im Schlamm vor. Die Liste erhebt keinen Anspruch auf Vollständigkeit, doch wurde darauf geachtet, dass alle nicht obligat parasitischen Familien aus Bergeys Manual [5] darin vertreten sind.

Eine weitere Unterteilung der Pseudomonadaceen wäre, nach der Auswertung der Versuche, wünschenswert, ist aber mit dem vorgelegten Satz von Merkmalen (Tab.2) nicht erreichbar. Das die Benennung ausführende Programm arbeitete nach folgendem Algorithmus: Von jedem Isolat $=$ OTU (original taxonomic unit, d.h. primäre taxonomische Einheit) wird berechnet, welche Ähnlichkeit es mit jedem der Standardtaxa aufweist. Anders als in der normalen Clusteranalyse üblich wurden dabei die Eigenschaften noch mit einer taxonomischen Bewertung gewichtet. Die Eigenschaften der Standardtaxa wurden etwas anders codiert als diejenigen der OTUs, da auch die Verneinung einer Eigenschaft codierbar sein musste. Dabei bedeuten:

A-N $=$ Merkmale und

$\mathrm{Z}-\mathrm{O}=$ nicht diese Merkmale, d. $\mathrm{h}$.

$\mathrm{Z}=$ nicht $\mathrm{A}$

$\mathrm{Y}=$ nicht $\mathrm{B}$ usw.

Als weitere Codierungen wurden benutzt:

$1=\mathrm{A}$ oder $\mathrm{B}$

$2=\mathrm{A}$ oder $\mathrm{B}$ oder $\mathrm{C}$

$3=\mathrm{A}$ oder $\mathrm{B}$ oder $\mathrm{C}$ oder $\mathrm{D}$

$4=$ A oder B oder C oder D oder E

$5=\mathrm{A}$ oder $\mathrm{B}$ oder $\mathrm{C}$ oder $\mathrm{D}$ oder $\mathrm{E}$ oder $\mathrm{F}$

$6=$ weder $A$ noch $B$

$7=$ D oder E

$8=\mathrm{C}$ oder $\mathrm{E}$ oder $\mathrm{G}$

$9=\mathrm{D}$ oder $\mathrm{E}$ oder $\mathrm{H}$

$+=\mathrm{D}$ oder $\mathrm{C}$

$-=$ A oder B oder E

3.42 Single link clustering (Gruppenbildung mit Suchen des ähnlichsten Nachbars)

Von je zwei Isolaten werden die einzelnen Merkmale miteinander verglichen und die Ähnlichkeit ausgerechnet. Für diese Ausrechnung existieren prinzipiell drei verschiedene Möglichkeiten (vgl. Jardine und Sibson [19]), welche sich mehr oder weniger ineinander überführen lassen. Die einfachste Näherung ist der sogenannte Match-Koeffizient: Die Eigenschaften werden miteinander verglichen und bei Übereinstimmung gezählt.

$$
\text { Match-Koeffizient }=\frac{\text { Anzahl gleicher Merkmale (E) }}{\text { Anzahl verglichener Merkmale (N) }} .
$$


Dieser Match-Koeffizient gilt streng nur für diskret unterscheidbare Merkmale und wurde hier für gleitende Merkmale, wie Bakterienlänge oder Koloniegrösse, wie folgt erweitert:

$$
\text { Ähnlichkeit }=\frac{E+\sum_{i=1}^{j} p_{i}}{N+j},
$$

wobei:

$\mathrm{p}_{\mathrm{i}}$ Wahrscheinlichkeit, dass Mittelwerte gleich (aus t-Test)

i Laufzahl der gleitenden Merkmale

j Anzahl der gleitenden Merkmale

Die Auswertung wurde nach dem Single-link-clustering-Verfahren durchgeführt. Im einzelnen wurde folgendermassen vorgegangen (= Single-link-cluster-Algorithmus):

a) Suche in der Matrix die (nächst-)höchste Ähnlichkeit. (Die Zeile und die Kolonne bezeichnen das entsprechende OTU-Paar.)

b) Wenn weder das eine noch das andere OTU bereits zu einer Gruppe gehört (dies ist beim Beginn der Analyse immer der Fall), bildet dieses Paar eine neue Gruppe.

c) Wenn eines der OTUs bereits zu einer Gruppe gehört, prüfe, wo es in dieser Gruppe steht, und füge das andere OTU entweder vorn oder hinten so dieser Gruppe zu, dass die beiden OTUs den kleinstmöglichen Abstand bekommen.

d) Wenn die beiden OTUs zu verschiedenen Gruppen gehören, vereinige diese Gruppen mit der analogen Abstandsbedingung von c.

e) Wenn beide bereits in derselben Gruppe sind, ändere nichts. (Diese Bedingung gibt das Single link.)

f) Gehe nach a, solange noch nicht alle OTUs in einer einzigen Gruppe sind.

In Abb. 2 ist ein Clusterdiagramm von Bakterien dargestellt. Es handelt sich um die vierte Probenahme von Versuch 3. (Zugehöriges Skylinediagramm mit den Bakteriennamen siehe Abb.7, S.336.) Das Skylinediagramm bildet etwa die Silhouette der dreidimensionalen Darstellung (Abb.2) der Ähnlichkeitsmatrix (Diagonalansicht).

Bei kleiner Artendiversität sind nur wenige "Wolkenkratzer» (=Cluster) mit tiefen Schluchten zu erkennen. Ist die Diversität gross, so bietet sich das Bild eines Hügels. Die Tatsache, dass der höchste Punkt etwa in der Mitte der Skyline liegt, wird durch die Minimalbedingung im Clusteralgorithmus verursacht (in Rubrik c und d).

Da die Ähnlichkeitsberechnungen für die Namen und für die Clusteranalyse verschieden sind, kann anhand dieser Diagramme auch die Namensgebung aus Kapitel 3.41 überprüft werden. 


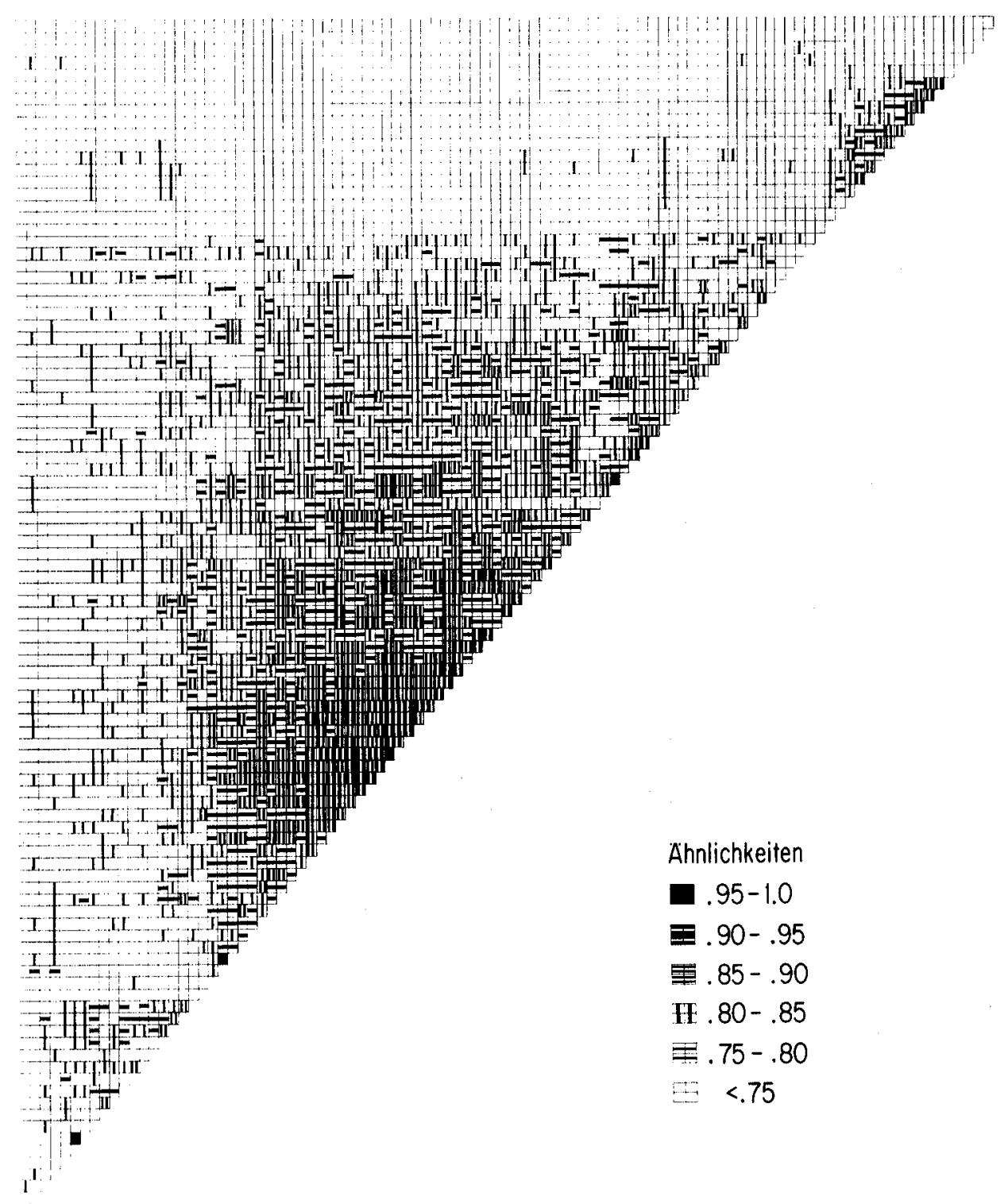

Abb.2. Clusterdiagramm bzw. sortierte Ähnlichkeitsmatrix der Bakterienpopulation 18 Tage nach der Zugabe von $8 \mathrm{~g}$ Algen $/ \mathrm{dm}^{2}$.

Figure 2. Cluster diagram, i.e. sorted similarities of bacteria 18 days after addition of $8 \mathrm{~g}$ algae/ $\mathrm{dm}^{2}$. sediment. The corresponding skyline diagram is figure $7 \mathrm{~b}$. 


\subsection{Information}

Die Formel nach Shannon und nach Wiener:

$$
H=-\sum_{i=1}^{n} p_{i 2} \log p_{i}
$$

berechnet die Summe der Einzelinformationen aus binären Einheiten. Diese Formel wurde von Margalef 1958 als «Diversitätsformel» angewendet. Williams et al. [48] erweiterten die Informationsformel von Individuen auf Merkmale wie folgt:

$$
I=k n \log n-\sum_{j=1}^{k} a_{j} \log a_{j}-\sum_{j=1}^{k}\left(n-a_{j}\right) \log \left(n-a_{j}\right),
$$

wobei:

k Anzahl Merkmale

n Anzahl OTUs

$a_{j}$ Anzahl OTUs, welche das j-te Merkmal besitzen

Mehrstufige Merkmale (mit q-Stufen) wurden als q-1-Merkmale behandelt. Die maximal mögliche Information, bei optimal verteilten Merkmalen, ist:

$$
I_{\max }=\mathrm{kn} \log 2 .
$$

Als Vergleich dazu: Die maximal mögliche Diversität ist:

$$
\mathrm{H}_{\max }={ }_{2} \log \mathrm{n} \text {. }
$$

Die experimentellen Daten wurden mit der beschriebenen Rechnungsmethode verarbeitet. Um den Fehler dieser Information angeben zu können, wurde jeweils für die Auswertung das Versuchsmaterial mit Hilfe von Zufallszahlen in drei gleiche Stichproben unterteilt und die Information jeder Stichprobe einzeln berechnet. Von den drei berechneten Informationen wurde nun die Standardabweichung berechnet.

\subsection{Das Temperatur-Wachstumsoptimum der Bakterien}

Das Volumen der Bakterienkolonien wurde zwischen den gemessenen Temperaturen linear interpoliert. Mit dem so ergänzten Datensatz wurde das Integral nach der Temperatur gebildet (Summierung) und in prozentuale Werte umgerechnet. Aus diesem Streckenzug wurden der 5\%-, 10\%-, 16\%-, 31\%-, 50\%-, 69\%-, 84\%-, $90 \%$ - und $95 \%$-Wert herausgelesen. Diese Werte bedeuten die Temperatur, bei der $5 \%$ usw. des potentiellen Wachstumsbereichs des Bakterienstamms erreicht sind.

Diese Prozedur wird für alle Bakterien des betreffenden Versuchs wiederholt. Als Resultat hat man nun bis zu 120 verschiedene Temperaturkurven, welche durch die herausgelesenen Werte (5 Summenprozent usw.) charakterisiert werden. Nun 
werden die prozentualen Summenhäufigkeitskurven dieser Werte nach dem gleichen Schema verarbeitet wie vorher die Summenhäufigkeitskurven des Temperaturbereichs eines Bakterienstamms. Auch hier werden die 5\%-, 10\%- usw. -Grenzen gesucht. Nun werden die beidseitigen Summenhäufigkeiten des ersten Verfahrens mit den beidseitigen Summenhäufigkeiten des zweiten Verfahrens graphisch kombiniert und ergeben eine zweidimensionale Summenhäufigkeitsdarstellung (Abb.9). Die Resultate dieses Verfahrens werden in Kapitel 5.3 diskutiert.

\section{Experimente und Resultate}

\subsection{Vorversuch}

Prüfung der Probenahmefrequenz, Versuchsdauer und Bebrütungsdauer: Aus einem Sedimentkern wurden verschiedene Proben gezogen (vgl. 3.32), davon das Trockengewicht bestimmt und eine Verdünnungsreihe auf Standardplatten angelegt. Nach den ersten zwei Probenahmen wurden $2 \mathrm{~g}$ Chlorella (Nassgegewicht $) / \mathrm{dm}^{2}$ in das überstehende Wasser zugefügt. Die Entwicklung der Bakterien im Sedimentkern wurde während der nächsten 24 Tage verfolgt. Die Keime wurden zu verschiedenen Zeiten gezählt. $\mathrm{Zu}$ Beginn der Bebrütung liegen theoretisch alle Keime als Einzelzellen vor. Zählbar werden die Keime bzw. Kolonien erst, wenn sie eine gewisse (sichtbare) Minimalgrösse überschreiten. Die Zeit bis zum Übersteigen dieser Grenze ist abhängig von der Länge der lag-Phase und der Wachstumsgeschwindigkeit der Keime; beide Kriterien sind stammspezifisch. Zur Überimpfung sollten die Keime am besten aus der log-Phase oder mindestens am Beginn der stationären Phase entnommen werden. Wie weitere Versuche zeigten, war ein Úbertragung selten erfolgreich, wenn die Kolonie weniger als $0,4 \mathrm{~mm}$ Durchmesser zeigte. Diese beiden Forderungen ergeben eine mögliche Bebrütungszeit von 5 bis 12 Tagen, wobei allerdings bei 5 Tagen erst etwa die Hälfte aller möglichen Keime sichtbar war (Abb.3). Für die folgenden Versuche

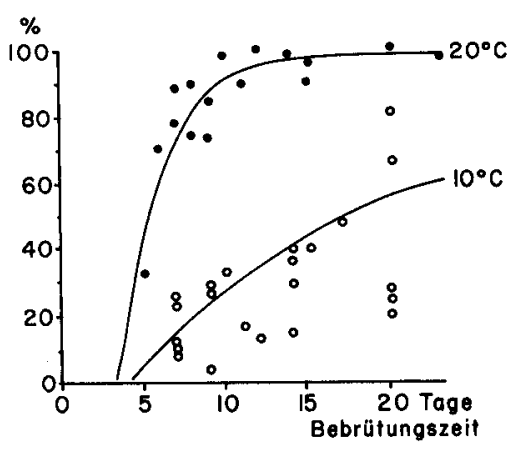

Abb.3. Abhängigkeit der Keimzahlzählwerte von der Bebrütungsdauer und der Bebrütungstemperatur. Figure 3. Relative values of plate count as function of time and incubation temperature. 


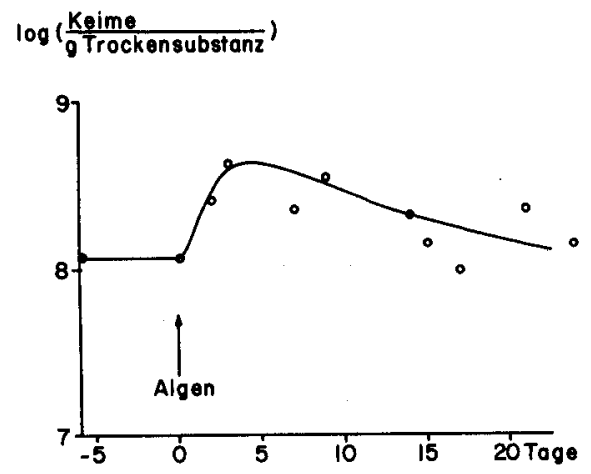

Abb.4. Verlauf der auf unendlich lange Bebrütungszeit extrapolierten Keimzahlen während des Vorversuchs (Zugabe von Algen).

Figure 4. Cell counts extrapolated for infinite incubation time versus time during preexperiment (addition of algae).

wurde deshalb eine Bebrütungsdauer von 7 Tagen gewählt. Wenn das Maximum der Keimzahlen bestimmt werden soll (und die folgenden Versuche gleich verlaufen wie dieser), muss die Störung des Sediments 3 bis 4 Tage vor der zweiten Probenahme erfolgen (vgl. Abb.4).

\subsection{Versuche 1 bis 4}

\section{Versuch 1}

Versuchsbedingungen: 4 Tage nach der ersten Probenahme wurden 1 g Heizöl EL, angerieben in $5 \mathrm{~g}$ Aluminiumoxid neutral (Firma M. Woelm, Eschwege, BRD) und suspendiert in $200 \mathrm{ml}$ sterilem destilliertem Wasser, zugegeben. Am 3., 10. und 17. Tag nach dieser Zugabe erfolgten die weiteren Probenahmen.

Bei der Probenahme aus den obersten Millimetern des Sediments strömt eine unbekannte Menge von überstehendem Wasser mit in die Spezialpipette. Das Nassgewicht hat also einen variablen Sedimentanteil und ist deshalb als Bezugsgrösse ungeeignet. Der Glührückstand, welcher normalerweise für Sedimente als konservativster Parameter gilt, scheidet aus, da das Heizöl mit Alox vermischt zugegeben wurde. Als einziger Gewichtsparameter bleibt also der Glühverlust, welcher im folgenden als konservativ angesehen wird. Da alle Literaturangaben auf ein Gramm Trockengewicht bezogen sind, wurden alle Zahlen mit einem konstanten Faktor von 0,13 multipliziert. Dieser Faktor entspricht dem 1,5jährigen Durchschnitt des Glühverlustanteils der Trockensubstanz des Sediments der Probestelle Horwer Bucht.

In der Tabelle 4 kann der zeitliche Verlauf der Keimkonzentrationen verfolgt werden ${ }^{2}$ ). Der Übergang von -4 Tagen auf 0 Tage wurde rechnerisch durchgeführt. Er entspricht der Verdünnung der Bakterienkonzentration durch etwa 50\%

2) Die Urdaten sind in der Bibliothek der EAWAG archiviert. 
zugegebene sterile Substanzmenge. Der Vergiftungseffekt war für die kultivierbaren Keime grösser als für die Totalzahl. Möglicherweise trat auch eine Wachstumshemmung auf, wofür die kleinere mittlere Koloniegrösse auf den Standardplatten spricht. Während des weiteren Versuchsverlaufs zeigte sich bei den gezählten Kategorien eine Zunahme der Keime, welche aber beim Versuchsabbruch nach 17 Tagen die ursprünglichen Konzentrationen noch nicht erreicht hatten.

Tabelle 4. Bakterienzählwerte von Versuch 1. (Die Zählwerte sind als ${ }_{10} \log$ pro g Trockensubstanz angegeben.)

Table 4. Bacteria counts of first experiment $\left(100 \mathrm{~g}\right.$ fuel oil per $\left.\mathrm{m}^{2}\right)$. (Counts are given as ${ }_{10} \mathrm{log}$ per g dry substance.)

\begin{tabular}{rllllr}
\hline $\begin{array}{l}\text { Zeit } \\
\text { Tage }\end{array}$ & Direktzahl & $\begin{array}{l}\text { Gesamt- } \\
\text { keimzahl }\end{array}$ & Anaerobier & $\begin{array}{l}\text { Gasprodu- } \\
\text { zenten }\end{array}$ & $\begin{array}{r}\text { Kultivier- } \\
\text { bare (\%) }\end{array}$ \\
\hline-4 & 8,122 & 6,345 & 4,353 & 2,762 & 1,67 \\
0 & 7,948 & 6,171 & 4,179 & 2,588 & 1,67 \\
3 & 7,326 & 5,178 & 3,310 & 2,347 & 0,69 \\
10 & 7,59 & 7,03 & 3,66 & 2,36 & 26,98 \\
17 & 7,69 & 6,88 & 3,18 & 2,61 & 15,53 \\
\hline
\end{tabular}

Tabelle 5. Verteilung der Bakterien aus Versuch 1 auf «Arten». (Die Kolonne jeweils hinter der Artzahl bedeutet die mittlere Ähnlichkeit der Bakterien mit dem vorgelegten Standardtaxon.) Table 5. Distribution of bacteria on 'species'. (Column after 'species' number is the mean similarity of named bacteria with standard taxon.)

\begin{tabular}{|c|c|c|c|c|c|c|c|c|}
\hline . & \multicolumn{2}{|c|}{-4 Tage } & \multicolumn{2}{|c|}{3 Tage } & $\begin{array}{l}10 \mathrm{Ta} \\
\mathrm{Zahl}\end{array}$ & 10 Tage & $\begin{array}{l}17 \mathrm{Ta} \\
\text { Zahl }\end{array}$ & Ähnl. \\
\hline Myxobacteriales & 1 & 0,784 & 1 & 0,784 & 1 & 0,784 & - & - \\
\hline Caulobacter & - & - & - & - & 2 & 0,813 & - & - \\
\hline Spirillum sp. & - & - & - & - & 1 & 0,869 & - & - \\
\hline Pseudomonas (deae) & 42 & 0,892 & 46 & 0,887 & 75 & 0,878 & 70 & 0,889 \\
\hline Pseudomonas putida & 1 & 0,911 & 4 & 0,887 & 1 & 0,858 & - & - \\
\hline Pseudomonas oleovorans & - & - & 1 & 0,933 & - & - & - & - \\
\hline Xanthomonas sp. & - & - & 1 & 0,844 & 1 & 0,873 & 1 & 0,855 \\
\hline Enterobacteriaceae & - & - & - & - & 1 & 0,875 & - & - \\
\hline Vibrioide & 4 & 0,881 & 4 & 0,868 & 12 & 0,882 & 10 & 0,898 \\
\hline Flavobacterium aquatile & 2 & 0,876 & - & - & 1 & 0,858 & - & - \\
\hline Gramnegative Micrococcen & 20 & 0,886 & 5 & 0,868 & 5 & 0,880 & 5 & 0,888 \\
\hline Grampositive Micrococcen & 2 & 0,888 & 8 & 0,872 & 2 & 0,869 & 1 & 0,844 \\
\hline Bacillus sp. & 3 & 0,793 & 5 & 0,879 & 4 & 0,862 & 2 & 0,844 \\
\hline Bacillus subtilis & 4 & 0,812 & 5 & 0,815 & - & - & - & - \\
\hline Bacillus megaterium & 4 & 0,784 & 2 & 0,765 & 2 & 0,789 & 1 & 0,799 \\
\hline Thermophile Bacillen & - & - & 2 & 0,783 & - & - & - & - \\
\hline Sporosarcina sp. & - & - & 1 & 0,809 & 1 & 0,810 & 1 & 0,809 \\
\hline Corynebacterium sp. & - & - & 2 & 0,832 & 1 & 0,813 & - & - \\
\hline Corynebacterium fimi & 1 & 0,755 & - & - & - & - & - & - \\
\hline Actinomycetaceae & 3 & 0,800 & 1 & 0,850 & 2 & 0,850 & - & - \\
\hline
\end{tabular}

Die «Artenzahlen» aus Versuch 1 sind in Tabelle 10 zusammengestellt. Angegeben sind: Anzahl OTUs jevorgelegten Namen sowie das arithmetische Mittel der Ähnlichkeiten (siehe 3.41), mit welchem sie dem Namen zugeordnet wurden. Die 


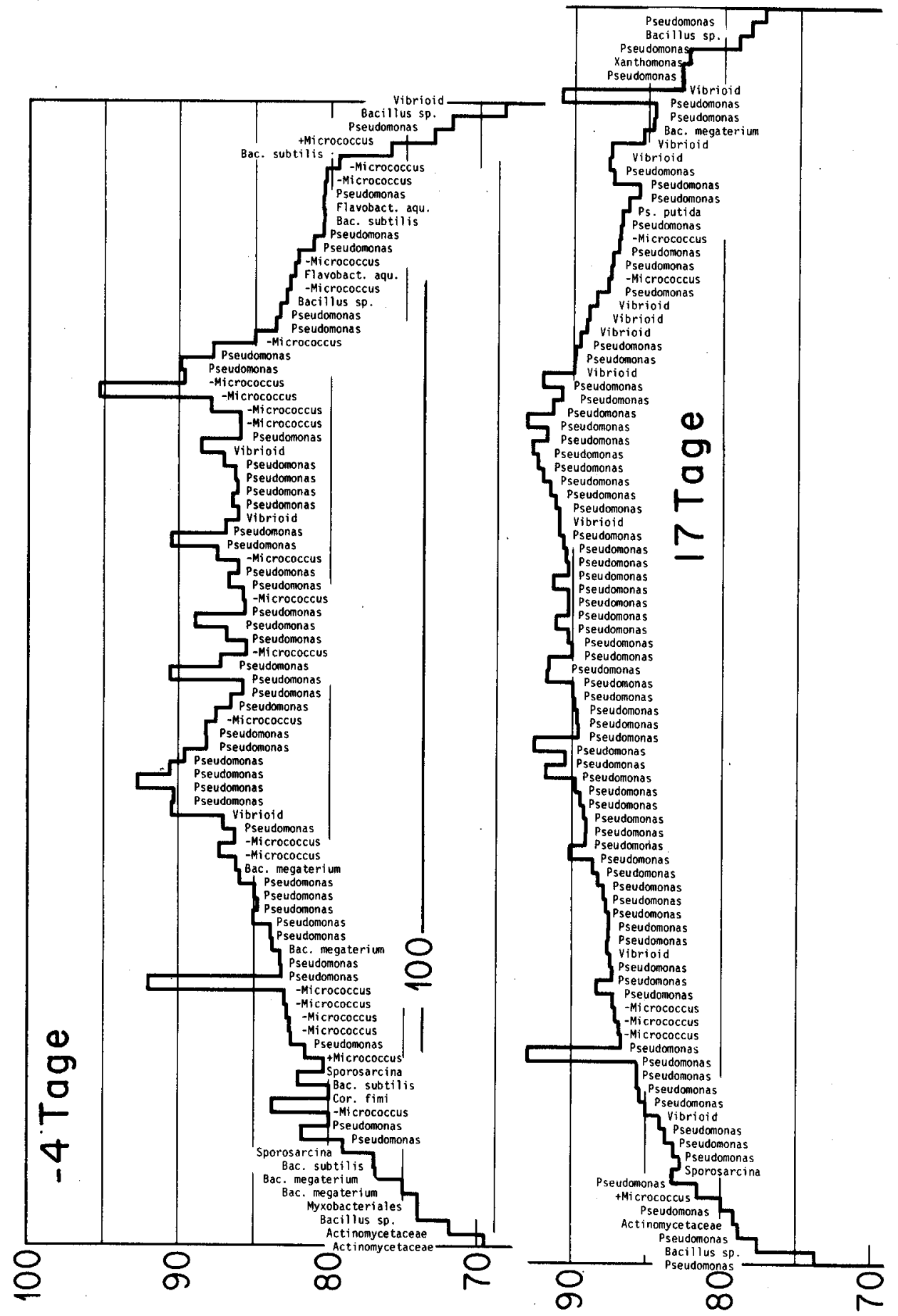

Abb. 5. Skylinediagramme des Versuchs 1.

Figure 5. Skyline diagrams of 1 st experiment $\left(100 \mathrm{~g}\right.$ fuel oil $/ \mathrm{m}^{2}$ ). 
Daten zeigen, dass während des Versuchs anscheinend eine Artenverschiebung zugunsten der nichtsporulierenden Bakterien stattfand. Diese relative Abnahme der sporulierenden Bakterien wird aber zu einer Vermehrung um etwa $25 \%$, wenn angenommen wird, dass die Auswahl bei Phase 16 proportional zur Anzahl der Kultivierbaren (Phase 5 bzw. 7) erfolgte.

Die Auswertung der Clusteranalyse ist in Abb.5 als Skylinediagramm dargestellt. Wie für ein ungestörtes Sediment zu erwarten war, sind bei -4 Tagen die letzten OTUs (Actinomyceten) erst bei niedrigen Ähnlichkeiten zum Einheitscluster gestossen. Beim Ähnlichkeitsniveau von $90 \%$ lassen sich 5 Cluster («Wolkenkratzer») voneinander unterscheiden. Auf dem gleichen Niveau sind 3 Tage nach der Zugabe des Heizöls nur noch 3 Cluster trennbar. Die mittleren höchsten Ähnlichkeiten (graphisch dargestellt durch die waagrechten Striche) steigen auf höhere Werte, was sich auch in der Informationssumme (siehe 5.6) zeigt. Das Niveau dieser grössten Ähnlichkeiten sinkt gegen Ende des Versuchs wieder, erreicht aber den Anfangszustand noch nicht. Wie schon in Kapitel 3.42 vermutet wurde, sieht man, dass bei diesem Clusterverfahren die Gattung Bacillus auf beide Enden des Clusters verteilt wird. Die Familie der Pseudomonadaceen bildet den Kern. (Hieraus lässt sich lediglich folgern, dass der Satz der vorgelegten Merkmale die Pseudomonaden schlecht voneinander trennt.) Der sanfte Hügel bei 17 Tagen zeigt keine grosse Diversität. (Die Form der Skyline muss zusammen mit dem mittleren Niveau betrachtet werden.)

\section{Versuch 2}

Gemäss Versuch 1 hat eine Belastung von $1 \mathrm{~g}$ Heizöl $/ \mathrm{dm}^{2}$ Sedimentfläche eine verhältnismässig grosse Vergiftung bzw. Wachstumshemmung zur Folge. Gemessen an den bisherigen Ölunfällen in Binnengewässern des Alpengebietes (vgl. Tab. 13) ist diese Belastung extrem hoch, jedenfalls kaum realistisch. Im Versuch 2 wurde sie deshalb auf $1 / 10$ verkleinert.

Versuchsbedingungen: 4 Tage nach der ersten Probenahme aus einem Sedimentkern wurden $0,1 \mathrm{~g}$ Heizöl EL, in $1 \mathrm{~g}$ sterilem Alox angerieben und in $100 \mathrm{ml}$ Seewasser suspendiert, zugegeben. Im Verlauf des Versuchs ergaben sich die in Tabelle 6 aufgeführten Keimzahlen.

Mit dieser Dosierung des Heizöls war die Giftwirkung erheblich schwächer als in Versuch 1. Bei den saprophytischen Anaerobiern erreichte sie erst nach 10 Tagen ein Maximum von $78 \%$. Nach 24 Tagen war die ursprüngliche Besiedelungsdichte des Substrats für alle Zählkategorien ungefähr wieder erreicht.

Auch in Tabelle 6 entspricht die Zeile für 0 Tage der rechnerischen Verdünnung der Bakterien durch die sterile Zugabe, welche diesmal etwa 30\% ausmachte. Der zeitliche Verlauf der Zuordnung der Namen ist in Tabelle 7 zusammengestellt. Beim Vergleich mit der "Artenverteilung» von Versuch 1 fällt der grosse Anteil der Bacillaceen auf, welcher sich durch den ganzen Versuch zieht. Aus dieser Tatsache kann geschlossen werden, dass keine explosionsartige Entwicklung erfolgte. Aus den Versuchen 1 und 2 kann man sehen, dass sich die sporulierenden Bakterien offenbar langsamer vermehren als die nichtsporulierenden, 
Tabelle 6. Bakterienzählwerte von Versuch 2. (Die Zählwerte sind als 10 log pro g Trockensubstanz angegeben.)

Table 6. Bacteria counts of 2 nd experiment $\left(10 \mathrm{~g}\right.$ fuel oil per $\left.\mathrm{m}^{2}\right)$. (Counts are given as ${ }_{10} \log$ per $\mathrm{g}$ dry substance.)

\begin{tabular}{rllllr}
\hline $\begin{array}{l}\text { Zeit } \\
\text { Tage }\end{array}$ & Direktzahl & $\begin{array}{l}\text { Gesamt- } \\
\text { keimzahl }\end{array}$ & Anaerobier & $\begin{array}{l}\text { Gasprodu- } \\
\text { zenten }\end{array}$ & $\begin{array}{r}\text { Kultivier- } \\
\text { bare (\%) }\end{array}$ \\
\hline-4 & 8,049 & 6,587 & 3,856 & 2,688 & 3,5 \\
0 & 7,933 & 6,481 & 3,740 & 2,572 & 3,5 \\
3 & 7,862 & 6,278 & 3,346 & 2,185 & 2,6 \\
10 & 7,387 & 5,822 & 3,934 & 2,326 & 2,7 \\
17 & 7,657 & 5,983 & 3,978 & 2,693 & 2,1 \\
24 & 7,651 & 6,028 & 3,563 & 1,859 & 2,4 \\
73 & 7,305 & 6,108 & 4,193 & 2,365 & 6,4 \\
\hline
\end{tabular}

Tabelle 7. Verteilung der Bakterien aus Versuch 2 auf «Arten» (vgl. Bemerkung in Tab.5).

Table 7. Distribution of bacteria on 'species' (cf. remark in table 5).

\begin{tabular}{|c|c|c|c|c|c|c|c|c|}
\hline & \multicolumn{2}{|c|}{-4 Tage } & \multicolumn{2}{|c|}{3 Tage } & \multicolumn{2}{|c|}{10 Tage } & \multicolumn{2}{|c|}{17 Tage } \\
\hline & Zahl & Ähnl. & Zahl & Ähnl. & Zahl & Ähnl. & Zahl & Ähnl \\
\hline Hyphomicrobium sp. & 1 & 0,833 & 1 & 0,817 & 1 & 0,854 & 1 & 0,903 \\
\hline Caulobacter sp. & - & - & 1 & 0,813 & - & - & - & - \\
\hline Pseudomonas (deae) & 58 & 0,875 & 46 & 0,878 & 64 & 0,883 & 67 & 0,884 \\
\hline Pseudomonas putida & - & - & - & - & 8 & 0,885 & 6 & 0,887 \\
\hline Pseudomonas oleovorans & 2 & 0,874 & 1 & 0,893 & 3 & 0,995 & - & - \\
\hline Xanthomonas sp. & 1 & 0,861 & - & - & - & - & - & - \\
\hline Vibrioide & 20 & 0,869 & 46 & 0,876 & 18 & 0,879 & 14 & 0,896 \\
\hline Flavobacterium aquatile & - & - & - & - & 1 & 0,878 & 2 & 0,836 \\
\hline Gramnegative Micrococcen & 3 & 0,886 & 2 & 0,869 & 5 & 0,868 & 2 & 0,869 \\
\hline Bacillus sp. & 19 & 0,868 & 3 & 0,856 & 9 & 0,880 & 13 & 0,859 \\
\hline Bacillus subtilis & 3 & 0,815 & 4 & 0,860 & 3 & 0,877 & 3 & 0,896 \\
\hline Bacillus megaterium & 1 & 0,896 & - & - & - & - & 3 & 0,870 \\
\hline Bacillus polymyxa & 1 & 0,838 & - & - & - & - & - & - \\
\hline Thermophile Bacillen & - & - & - & - & - & - & 1 & 0,870 \\
\hline Corynebacterium sp. & 2 & 0,857 & 5 & 0,830 & - & - & 1 & 0,849 \\
\hline Corynebacterium fimi & - & - & 1 & 0,804 & - & - & - & - \\
\hline Actinomycetaceae & 2 & 0,800 & 1 & 0,850 & 2 & 0,850 & 1 & 0,850 \\
\hline Mycobacterium album & - & - & - & - & - & - & 1 & 0,753 \\
\hline
\end{tabular}

während die Unempfindlichkeit der Sporen gegenüber Giften einen Selektionsvorteil für die Bazillen bedeutet. (Natürlich bilden auch Pseudomonaden Dauer- bzw. Ruhestadien, zymogene Keime [22], welche bei der Direktzählung reichlich beobachtet wurden.) Bei allen hier bestimmten Keimzahlen muss bedacht werden, dass entweder die Zahl aller Bakterien (Direktzählung) oder die Zahl der keimfähigen bzw. züchtbaren bestimmt wurde, aber nie die Zahl der jeweils aktiven.

Skylinediagramme dieses Versuchs finden sich in Abb.6. Bei diesem Versuch erfolgte ein Anstieg des mittleren Niveaus der Skyline von etwa $86 \%$ bei -4 Tagen auf etwa $90 \%$ bei 3 Tagen, worauf das mittlere Niveau gegen Ende des Versuchs wieder etwa den Anfangswert erreichte, d.h. die Population wies kurz nach der Störung eine höhere mittlere Ähnlichkeit auf. Ein typisches Hervortreten von einigen wenigen, gut voneinander getrennten Clustern war nicht zu beobachten. 


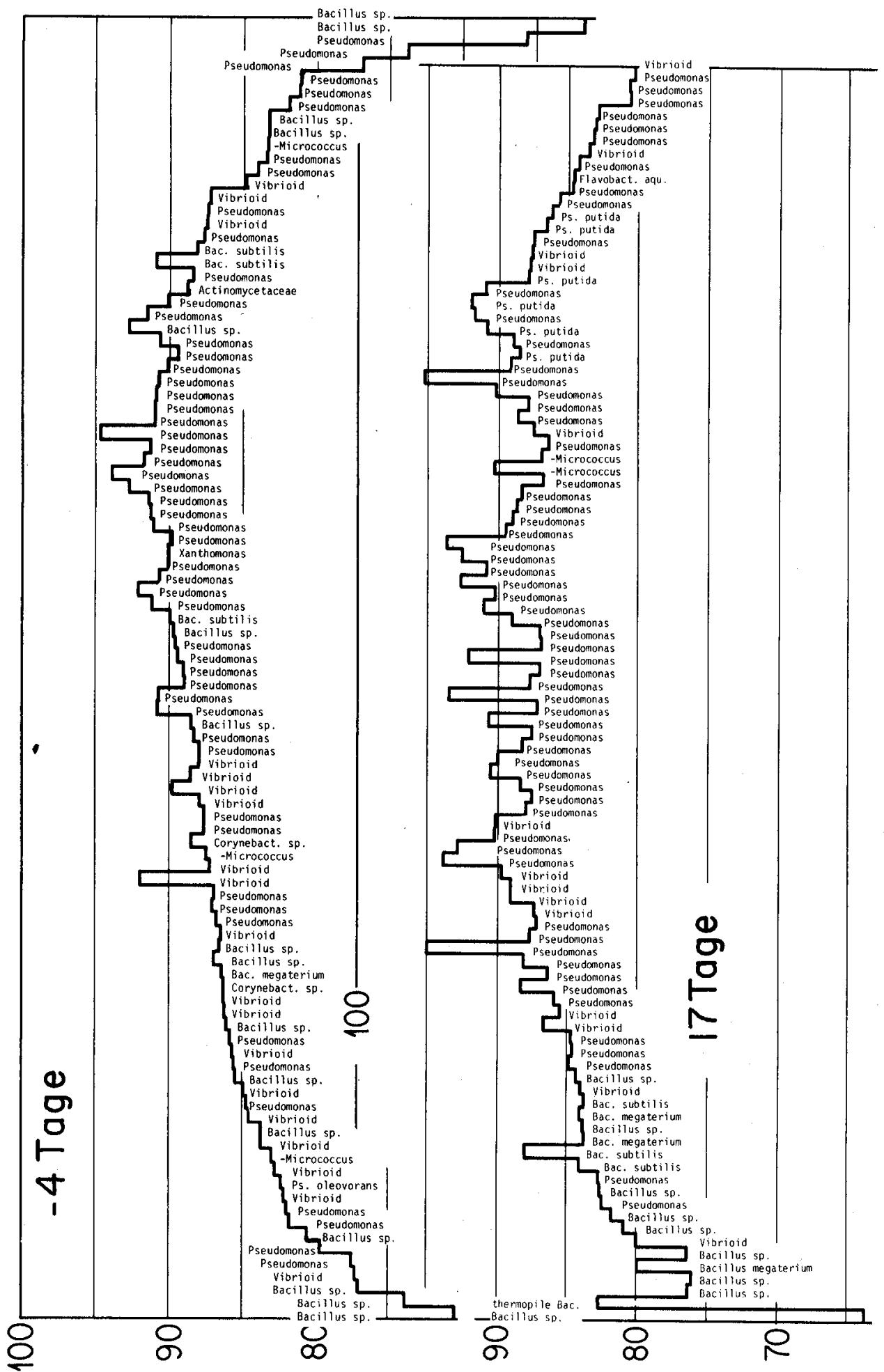

Abb.6. Skylinediagramme des Versuchs 2.

Figure 6. Skyline diagrams of 2 nd experiment ( $10 \mathrm{~g}$ fuel oil $/ \mathrm{m}^{2}$ ). 
Dies bedeutet eine hohe Diversität, wofür auch die vielen «Wolkenkratzer» bei 17 Tagen sprechen. Bei der Nullerprobe (bzw. -4 Tage) fällt auf, dass sich Bacillus sp. sogar unter die Pseudomonaden verschoben haben, was bei einer Gewichtung der Merkmale nach ihrem taxonomischen Wert nicht geschehen wäre.

\section{Versuch 3}

In den Versuchen 1 und 2 wurde das Bakterienökosystem durch eine Heizölzugabe gestört. Es ist denkbar, dass sich die festgestellten Veränderungen auch durch die Zugabe einer natürlichen, d.h. autochthon gebildeten Kohlenstoffquelle erzielen lassen.

Versuchsbedingungen: 3 Tage nach der ersten Probenahme erfolgte eine Zugabe von 8 g (Nassgewicht) Chlorella pyrenoidosa (Stamm 211-8b des Pflanzenphysiologi-

Tabelle 8. Bakterienzählwerte von Versuch 3. (Die Zählwerte sind als ${ }_{10}$ log pro g Trockensubstanz angegeben.)

Table 8. Bacteria counts of 3 rd experiment. (Counts are given as ${ }_{10} \log$ per $\mathrm{g}$ dry substance.)

\begin{tabular}{rllllr}
$\begin{array}{l}\text { Zeit } \\
\text { Tage }\end{array}$ & Direktzahl & $\begin{array}{l}\text { Gesamt- } \\
\text { keimzahl }\end{array}$ & Anaerobier & $\begin{array}{l}\text { Gasprodu- } \\
\text { zenten }\end{array}$ & $\begin{array}{r}\text { Kultivier- } \\
\text { bare (\%) }\end{array}$ \\
\hline-3 & 7,529 & 6,242 & 4,225 & 2,573 & 5,16 \\
0 & 7,059 & 5,772 & 3,755 & 2,103 & 5,16 \\
4 & 7,176 & 5,870 & 4,105 & 1,868 & 4,94 \\
11 & 7,421 & 6,601 & 4,150 & 1,426 & 15,14 \\
18 & 7,765 & 6,249 & 3,707 & 2,827 & 3,05 \\
25 & 7,631 & 6,133 & 3,959 & 1,509 & 3,18 \\
\hline
\end{tabular}

Tabelle 9. Verteilung der Bakterien aus Versuch 3 auf «Arten» (vgl. Bemerkung in Tab.5).

Table 9. Distribution of bacteria on 'species' (cf. remark in table 5).

\begin{tabular}{|c|c|c|c|c|c|c|c|c|}
\hline Name & $\begin{array}{l}-4 \mathrm{~T} \\
\text { Zahl }\end{array}$ & $\begin{array}{l}\text { Age } \\
\text { Ähnl. }\end{array}$ & $\begin{array}{l}3 \text { Tage } \\
\text { Zahl }\end{array}$ & Ähnl. & $\begin{array}{l}10 \mathrm{Ta} \\
\mathrm{Zahl}\end{array}$ & Ähnl. & $\begin{array}{l}17 \text { Tag } \\
\text { Zahl }\end{array}$ & Ähnl. \\
\hline Spirillum sp. & - & - & - & - & - & - & 2 & 0,813 \\
\hline Pseudomonas (deae) & 57 & 0,880 & 49 & 0,872 & 58 & 0,850 & 49 & 0,857 \\
\hline Pseudomonas fluoreszens & - & - & - & - & 1 & 0,851 & 1 & 0,851 \\
\hline Pseudomonas putida & 15 & 0,889 & 15 & 0,867 & 6 & 0,859 & 11 & 0,872 \\
\hline Pseudomonas oleovorans & 2 & 0,890 & - & - & 4 & 0,766 & 1 & 0,883 \\
\hline Xanthomonas sp. & - & - & 8 & 0,862 & 19 & 0,857 & 12 & 0,857 \\
\hline Vibrioide & 13 & 0,863 & 5 & 0,885 & 6 & 0,884 & 11 & 0,871 \\
\hline Flavobacterium aquatile & 4 & 0,857 & 11 & 0,865 & 7 & 0,837 & 3 & 0,846 \\
\hline Gramnegative Micrococcen & 2 & 0,860 & 3 & 0,866 & 1 & 0,880 & 1 & 0,851 \\
\hline Grampositive Micrococcen & 1 & 0,840 & - & - & - & - & - & - \\
\hline Bacillus sp. & 8 & 0,871 & 11 & 0,863 & 6 & 0,879 & 15 & 0,877 \\
\hline Bacillus subtilis & 2 & 0,775 & 7 & 0,826 & 2 & 0,871 & 4 & 0,896 \\
\hline Bacillus megaterium & - & - & 2 & 0,828 & - & - & 1 & 0,840 \\
\hline Bacillus polymyxa & - & - & 1 & 0,814 & - & - & - & - \\
\hline Corynebacterium sp. & 10 & 0,838 & 2 & 0,843 & 1 & 0,847 & 2 & 0,849 \\
\hline Actinomycetaceae & - & - & - & - & - & - & 1 & 0,850 \\
\hline Mycobacterium album & - & - & - & - & 2 & 0,726 & - & - \\
\hline «Bacterium sp.» & 1 & 0,855 & 1 & 0,862 & 1 & 0,832 & 1 & 0,851 \\
\hline
\end{tabular}




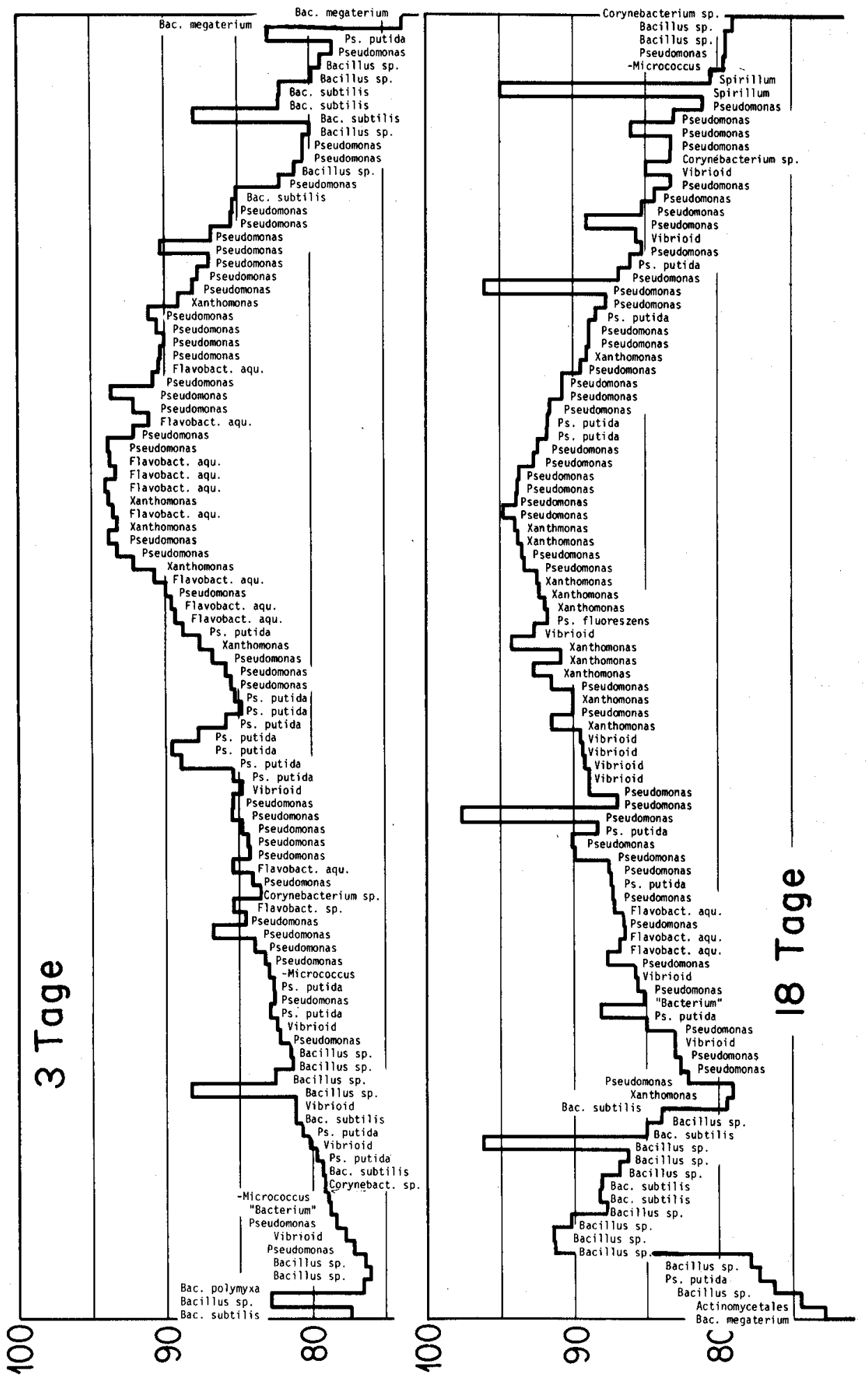

Abb.7. Skylinediagramme des Versuchs 3.

Figure 7. Skyline diagrams of $3 \mathrm{rd}$ experiment $\left(8 \mathrm{~g}\right.$ algae $\left./ \mathrm{dm}^{2}\right)$. 
schen Institutes, Göttingen, W. Koch), etwa $60 \%$ steril autolysiert, suspendiert in $100 \mathrm{ml}$ sterilfiltriertem Seewasser. In diesem Versuch wurde der Glührückstand als konservativer Parameter betrachtet und die Bakterienkonzentrationen dementsprechend umgerechnet.

Die Bakterien verhalten sich wie im Vorversuch; anscheinend werden sie nicht vergiftet. Das Verhalten der Direktzahlen ist in Kapitel 5.3 diskutiert. Das Absinken der Anaerobierzahl und somit auch die Veränderung bei den anaeroben Gasproduzenten dürfte ein Isolationsartefakt sein, da das Impfmaterial während der Verdünnung usw. der Luft ausgesetzt war.

Die «Arten»-Verteilung während des Versuchs 3 ist in Tabelle 9 zusammengestellt. Statistisch signifikante Artenverschiebungen sind nicht zu erkennen. (Sie waren auch nicht zu erwarten, wenn man bedenkt, dass eine Bakterienpopulation, welche während Jahren von sedimentierten Algen gelebt hat, nun wieder Algen als Futter bekommt.)

In Abb. 7 sind die Skylinediagramme dieses Versuchs dargestellt. Im Diagramm von 3 Tagen nach der Algenzugabe finden sich die Flavobacterium aquatile als Kern des Pseudomonadenclusters. Damit steigt der Verdacht, dass bei dieser Art der Namengebung Flavobact. aquatile identisch ist mit Pseudomonas sp. Der zeitliche Verlauf des mittleren Ähnlichkeitsniveaus gleicht demjenigen der Versuche 1 und 2, d.h. erst ein Anstieg und dann wieder ein langsames Abfallen. Es erfolgte eine Entwicklung zu einer Dominanz der Pseudomonadeae bei 11 Tagen, welche aus zwei gut getrennten Clustern bestand (Trenniveau $82 \%$ ).

\section{Versuch 4}

In den Versuchen 1-3 wurde die Wirkung der Belastung des Bakterienökosystems durch ein Kohlenwasserstoffgemisch bzw. durch natürliche Kohlenstoffverbindungen quantifiziert. Im natürlichen Gewässer kommen Ölbelastungen meist in Kombination mit einer vermehrten Algensedimentation vor (Zahner [18]). Im folgenden Experiment wurde die Auswirkung einer derartigen kombinierten Belastung geprüft. Als Ansatz wurde die Heizölzugabe des Versuchs 2 und eine gegenüber Versuch 3 verminderte Zugabe von Algen gewählt.

Versuchsbedingungen: 4 Tage nach der ersten Probenahme aus einem Sedimentkern wurden 0,1 g Heizöl EL, angerieben in $1 \mathrm{~g}$ Alox, und $2 \mathrm{~g}$ Chlorella (Nassgewicht), während 7 Minuten mit Ultraschall homogenisiert, alles suspendiert in $400 \mathrm{ml}$ sterilfiltriertem Seewasser, in das überstehende Wasser gegeben. Der zeitliche Verlauf der Keimzahlen ist in Tabelle 10 zusammengestellt. Eine Vergiftung wird bei diesem Versuchsansatz kaum manifest. Werte dieser Tabelle werden in Kapitel 5.5 diskutiert.

Die Tabelle 11 zeigt die Veränderung der OTUs im zeitlichen Ablauf des Versuchs 4. Aus der Tabelle geht hervor, dass eine Abnahme der sporulierenden Bakterien erfolgte. Wenn nun gleichzeitig der Verlauf der Gesamtkeimzahl berücksichtigt wird, stieg die Konzentration der Sporulierenden bis zum 10. Tag etwa um das 10fache. Die Heizöloxydanten vermehrten sich um das 40fache, und im mikroskopischen Bild zeigte sich, dass Algen und zumindest gewisse Bestandteile des Öls 
Tabelle 10. Bakterienzählwerte von Versuch 4. (Die Zählwerte sind als ${ }_{10} \log$ pro g Trockensubstanz angegeben.)

Table 10. Bacteria counts of 4th experiment. (Counts are given as ${ }_{10} \log$ per $g$ dry substance.)

\begin{tabular}{rllllr}
\hline $\begin{array}{l}\text { Zeit } \\
\text { Tage }\end{array}$ & Direktzahl & $\begin{array}{l}\text { Gesamt- } \\
\text { keimzahl }\end{array}$ & Anaerobier & $\begin{array}{l}\text { Gasprodu- } \\
\text { zenten }\end{array}$ & $\begin{array}{r}\text { Kultivier- } \\
\text { bare (\%) }\end{array}$ \\
\hline-4 & 7,722 & 5,584 & 4,006 & 2,525 & 0,73 \\
0 & 7,490 & 5,353 & 3,774 & 2,293 & 0,73 \\
3 & 7,339 & 6,152 & 3,843 & 3,099 & 6,5 \\
10 & 7,540 & 7,000 & 3,358 & 2,418 & 28,9 \\
17 & 7,774 & 6,980 & 3,383 & 2,679 & 16,0 \\
24 & 7,346 & 6,812 & 4,098 & 2,642 & 29,2 \\
\hline
\end{tabular}

Tabelle 11. Verteilung der Bakterien aus Versuch 4 auf «Arten» (vgl. Bemerkung in Tab.5).

Table 11. Distribution of bacteria on 'species' (cf. remark in table 5).

\begin{tabular}{|c|c|c|c|c|c|c|c|c|}
\hline Name & $-4 \mathrm{~T}$ & & $3 \mathrm{Tag}$ & & $10 \mathrm{Ta}$ & & $17 \mathrm{Ta}$ & \\
\hline & Zahl & Ähnl. & Zahl & Ähnl. & Zahl & Ähnl. & Zahl & Ähnl. \\
\hline Caulobacter sp. & 1 & 0,813 & - & - & 1 & 0,813 & - & - \\
\hline Pseudomonas (deae) & 51 & 0,885 & 62 & 0,885 & 75 & 0,881 & 74 & 0,883 \\
\hline Pseudomonas putida & 6 & 0,882 & 18 & 0,893 & 18 & 0,884 & 16 & 0,888 \\
\hline Pseudomonas oleovorans & 6 & 0,896 & 4 & 0,866 & 2 & 0,899 & 4 & 0,919 \\
\hline Xanthomonas sp. & - & - & - & - & - & - & 1 & 0,855 \\
\hline Enterobacteriaceae & 1 & 0,815 & - & - & - & - & - & - \\
\hline Vibrioide & 11 & 0,875 & 9 & 0,876 & 8 & 0,894 & 5 & 0,888 \\
\hline Gramnegative Micrococcen & 6 & 0,875 & 1 & 0,888 & 2 & 0,888 & 1 & 0,888 \\
\hline Grampositive Micrococcen & 1 & 0,851 & 1 & 0,851 & - & - & 2 & 0,851 \\
\hline Bacillus sp. & 12 & 0,858 & 10 & 0,867 & 3 & 0,879 & 5 & 0,842 \\
\hline Bacillus subtilis & 1 & 0,889 & - & - & 1 & 0,896 & - & - \\
\hline Sporosarcina sp. & 7 & 0,800 & 7 & 0,809 & - & - & - & - \\
\hline Corynebacterium $\mathrm{sp}$. & - & - & 1 & 0,806 & 3 & 0,825 & 6 & 0,819 \\
\hline Actinomycetaceae & 2 & 0,800 & - & - & - & - & - & - \\
\hline Mycobacterium phleï & 1 & 0,778 & - & -. & - & -. & - & - \\
\hline «acterium sp.» & 1 & 0,855 & 1 & 0,857 & - & - & 1 & 0,833 \\
\hline
\end{tabular}

gleichzeitig abgebaut werden. Dies bestätigt die dritte Variante der Abbaumöglichkeiten in Kapitel 2. Davis [9] und Kusnetzov [23] postulieren die Bildung der ersten Stufen von Erdöl in anoxischem Milieu; da aber alle Versuche aerob durchgeführt wurden, konnte nicht verifiziert werden, ob in diesem Fall nur noch die Algen abgebaut werden.

Die Skylinediagramme des Versuchs 4 sind in Abb. 8 dargestellt. Die gut isolierten Cluster der «Hungerskyline» bei -4 Tagen waren bei 3 Tagen verschwunden. Actinomycetaceae wurden auch nicht mehr isoliert; es ist aber kaum anzunehmen, dass diese vergiftet wurden, erscheinen doch in der Liste der kohlenwasserstoffverwertenden Organismen von Fuhs [13] einige Nocardia-Stämme, welche auch die von Fuhs meist als giftiger bezeichneten Aromaten abbauen können. Wahrscheinlicher ist ein Selektionsartefakt. Gegen Ende des Versuchs bildete sich ein Corynebacterium-Cluster, welcher andeutungsweise bereits nach 10 Tagen vorhanden war. Wie bei allen andern Versuchen gehört die Hauptmenge der Bakterien zu den Pseudomonadaceen, welche auch den Cluster mit der höchsten Ähnlichkeit bilden. 


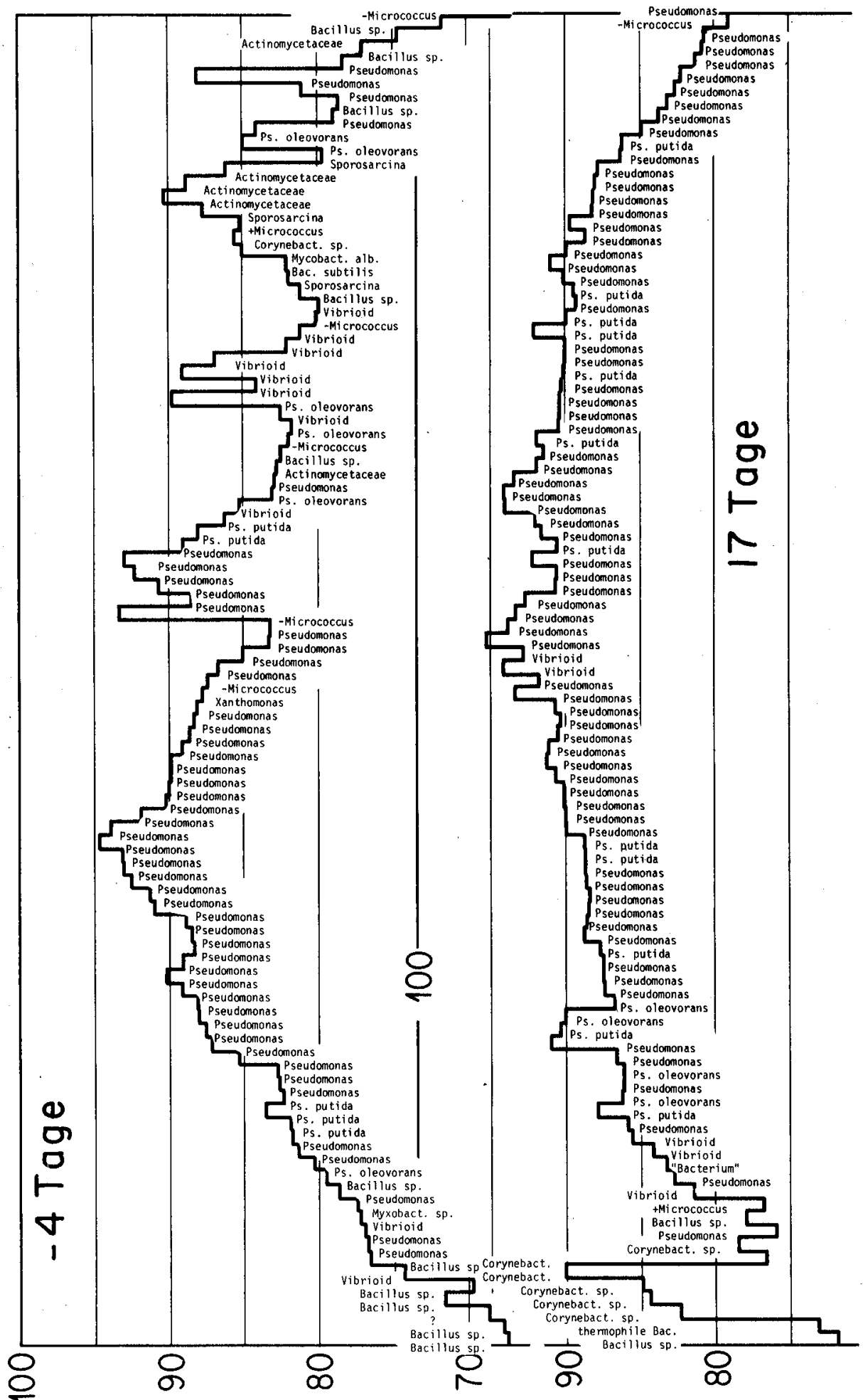

Abb.8. Skylinediagramme des Versuchs 4.

Figure 8. Skyline diagrams of 4 th experiment. 


\section{Diskussion}

\subsection{Nullexperiment}

Ein eigentliches Nullexperiment wurde aus folgenden Grunden nicht durchgefuhrt: Es hätte darin bestanden, einen unbeeinflussten Sedimentkern während mindestens 24 Tagen zu beobachten. Die Auswertung des Experimentes hätte die Streuung innerhalb dieses Kerns ergeben. Für den Vergleich der Versuche miteinander hätte noch die Streuung zwischen den Kernen gefehlt. Die Gesamtstreuung (d.h. die Streuung innerhalb und zwischen den Kernen) geht aus den Startbedingungen der Versuche hervor. Wie in Kapitel 5.2 erklärt, zeigen die Direktzählungen einen langfristigen Verlauf. Dieser wurde für alle Zählwerte durch Rückrechnung auf das Startdatum des ersten Versuchs eliminiert. Von diesen korrigierten Zahlwerten wurde eine Streuungszerlegung mit anschliessendem F-Test durchgeführt. Die Wahrscheinlichkeit, dass die Startwerte gleich sind, beträgt 0,375 , die Wahrscheinlichkeit, dass alle Werte gleich sind, beträgt weniger als 0,00005 (d.h. dies ist die Wahrscheinlichkeit, dass alle Direktzählungen unter sich und alle Gesamtkeimzahlen unter sich und alle Anaerobierzahlen unter sich gleich sind). Dies bedeutet: Zwar kann die Behauptung, dass die Sedimentkerne voneinander verschieden waren, nicht bewiesen werden, wohl aber, dass die Werte der Versuchsverläufe ausserhalb der statistischen Streuung der Startwerte liegen. Ähnliches gilt für die ermittelten OTUs bzw. ihre Zusammenfassung in die drei Kategorien gramnegative und -positive Eubakterien und übrige: Die Wahrscheinlichkeit, dass alle Startwerte gleich sind, ist hier 0,466 , während die Wahrscheinlichkeit, dass alle Versuchswerte gleich sind, nur 0,0001 beträgt.

\subsection{Langfristiger Verlauf der Keimzahlen in den Sedimentkernen}

Sämtliche Kerne für unsere Versuche wurden in einer einzigen Aktion gestochen und ins Labor transportiert. Anderseits nahm ein Versuch rund 2 Monate in Anspruch, so dass es möglich war, in den Kernen die langfristige Verănderung der Bakterienbiozönose zu beobachten.

Theoretisch müsste die Bakterienzahl im Laufe der Zeit exponentiell abnehmen, sofern nicht laufend neues Futter zugefügt wird. Die Abnahme der Bakterien betrug in unseren Kernen rund $80 \%$ pro Jahr, was etwa mit dem Abbau der organischen Substanz übereinstimmt, wenn man nur den innerhalb eines Jahres abbaubaren Anteil berücksichtigt (Bloesch [4]).

Der zeitliche Verlauf kann durch eine Regressionsrechnung formuliert werden:

$$
D_{t}=2,55 \cdot 10^{9} \cdot e^{-0,0062 t},
$$

wobei:

$t$ Zeit in Tagen

$D_{t}$ Direktzahl/g «Trockensubstanz» zur Zeit $t$

Korrelationskoeffizient $r=-0,94$ 


\subsection{Vergleich der Versuchsergebnisse anhand von Isoauxaten}

Als «Isoauxaten» bezeichnen wir Kurven, welche Punkte mit gleichem Wachstum miteinander verbinden $(a v \xi \varepsilon \tilde{i} v=$ wachsen). Vereinfachend kann als Modell eine bivariate Normalverteilung angenommen werden. Die Punkte gleicher Dichten bzw. gleicher Wachstumsintensitäten wären in diesem Fall Ellipsen. Je breiter diese Ellipsen sind, desto breiter war der mittlere optimale Wachstumsbereich der Bakterien bzw. desto eurythermer waren sie. Je steiler die Hauptachse der Ellipse ist, desto ähnlicher waren die Wachstumsoptima der Bakterien. Ihre Berechnung und Konstruktion ist in Kapitel 3.44 beschrieben. Auf der Abszisse des Bezugssystems sind die Temperatur in Grad Celsius und auf der Ordinate die Summenprozente,

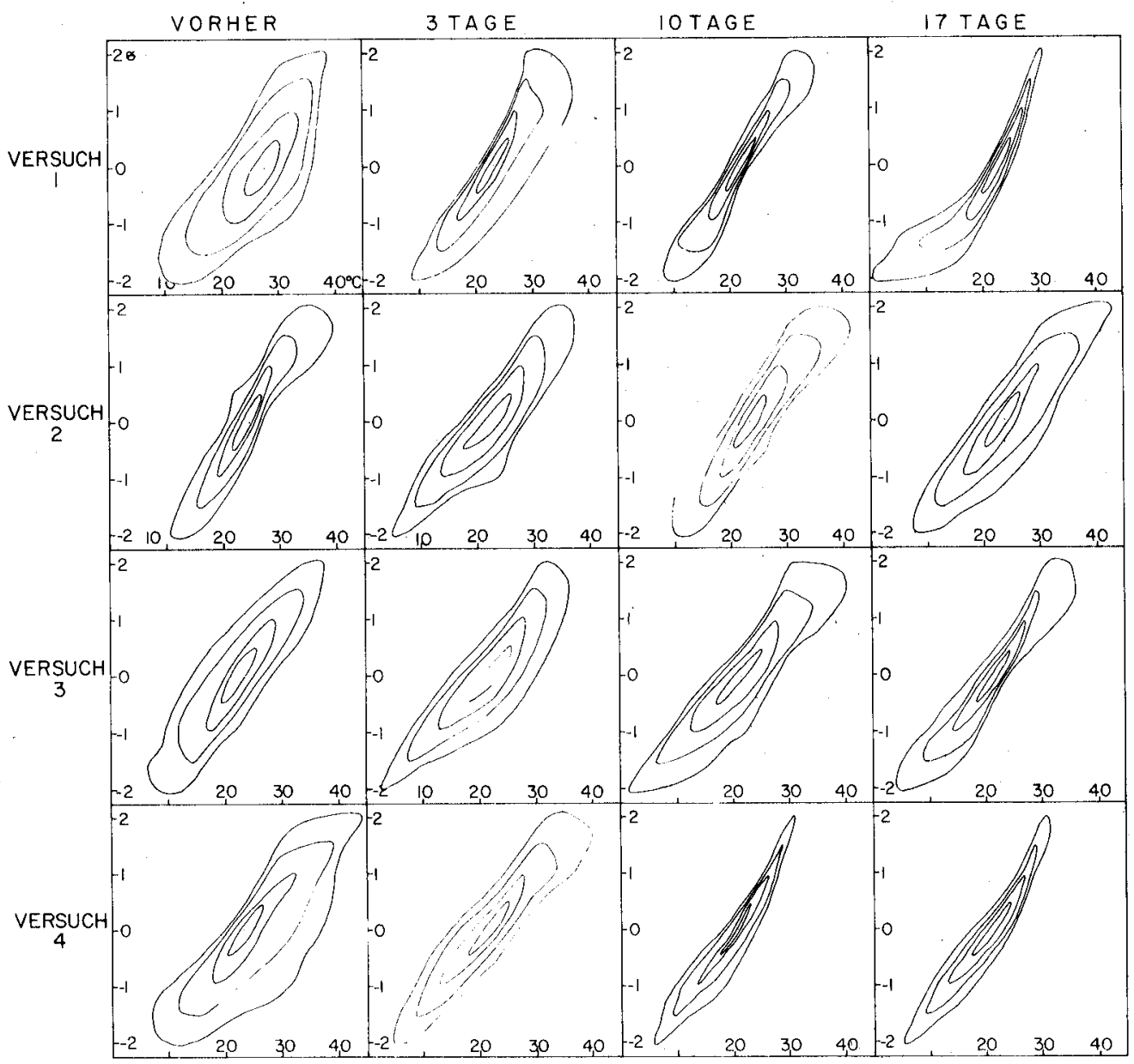

Abb.9. Isoauxaten bzw. Kurven gleichen Wachstums; die senkrechte Achse ist in Sigma-Schritten, die waagrechte in ${ }^{\circ} \mathrm{C}$ unterteilt (vgl. 5.3).

Figure 9. Isoauxates i.e. curves of equal growth. In the curves are, starting in the middle, 48, 70, 87 and $97 \%$ of growth of population. Narrowness of 'ellipses' can be used as measure of stenothermy and the steepness for equality of temperature dependency. 
nach dem Gaußschen Integral verzerrt ("Wahrscheinlichkeitsskala»), in Einheiten der Standardabweichung aufgetragen. Die Kurven umschreiben 97\%, 87\%, 70\% und $38 \%$ der Wachstumsbereiche der zusammengesetzten Populationen.

Wie in den Kapiteln 5.5 und 5.6 folgt, findet in Versuch 1 (hohe KW-Belastung) ein Informationsverlust der Bakterienpopulation statt; das System wird vergiftet. Die Temperaturbereiche der Bakterien werden kleiner, d.h. die stenothermen Bakterien werden selektioniert, und vom 10. auf den 17. Tag scheint eine Selektion der Psychrophilen stattzufinden, möglicherweise auch eine langsamere Reaktion der Psychrophilen infolge langsameren Stoffwechsels. Allerdings sprechen beobachtete Verdoppelungszeiten von etwa einer Stunde bei $4^{\circ} \mathrm{C}$ gegen eine solche Annahme.

Versuch 2 (niedere Heizölbelastung): Der Temperaturbereich und die übrige Information der Bakterienpopulation erweitern sich in diesem Versuch, was auf das zusätzliche Angebot von weiteren («ökosystemfremden») abbaubaren Verbindungen zurückgeführt werden kann.

Versuch 3 (Belastung mit Algen): Der Temperaturbereich wird etwas verkleinert, aber wahrscheinlich deshalb, weil der Anteil der kultivierbaren Bakterien verringert wird. Es könnte sich hier um einen Selektionsartefakt handeln, welcher in der Differenz zwischen der Zusammensetzung des «Standardnährbodens» und der Zusammensetzung der abbaubaren Stoffe im Sediment begründet ist.

Die Zugabe der Chlorellen bewegte sich in einem für Sedimentbakterien üblichen chemischen Rahmen; d.h. es wurden keine ökosystemfremden Stoffe zugeführt.

Versuch 4 (Algen und niedere Heizölbelastung): Beim Vergleich der Versuchsresultate 2, 3 und 4 fällt auf, dass der Versuch 4 nicht die Summe der Versuche 2 und 3 darstellt, sondern eher in Richtung des Versuchs 1 (grosse Heizölbelastung) geht. Dies kann folgendermassen erklärt werden: Bakterien in einem Ruhestadium haben einen reduzierten Stoffwechsel und nehmen im Falle einer Vergiftung offenbar auch weniger toxische Substanzen auf. Sind die Bakterien dagegen aktiv (als Folge des Kohlenstoffangebots), so steigt auch die Wirkung toxischer Stoffe, hier Bestandteile des Heizöls.

\subsection{Simulationen der kurzfristigen Versuchsverläufe}

Die in Kapitel 4 erwähnten Giftwirkungen wurden dort so berechnet, als ob eine Monokultur von Bakterien vorhanden wäre, welche mit der Zeit linear wächst, bzw. stirbt. Da dies sicher nicht der Fall war, soll nun mit Hilfe eines einfachen Modells eine Mischkultur mit zwei bezüglich Giftwirkung unterscheidbaren Populationen simuliert werden.

a) Ein gewisser Anteil der Gesamtpopulation wird vergiftet und stirbt. Er wird im folgenden als $y_{1}$ bezeichnet.

$$
\frac{d y_{1}}{d t}=-c_{1} y_{1} ; \quad c_{1}=\text { Sterberate in } \mathrm{Tg}^{-1} \text {. }
$$

Die Gleichung (8) entspricht dem üblichen Ansatz für Sterbekurven und ergibt integriert eine exponentiell abfallende Kurve. 
b) Ein gewisser Anteil der Gesamtpopulation y erhält das für ihn spezifische Futter und wächst $\left(\mathrm{y}_{2}\right)$.

$$
\frac{d y_{2}}{d t}=c_{2} y_{2}\left(1-y_{2} / y_{3}\right) ; \quad c_{2} \text { in } \mathrm{Tg}^{-1} .
$$

$c_{2}$ ist die messbare Vermehrungsrate, welche additiv aus der wirklichen Vermehrungsrate und der aktuellen Sterberate zusammengesetzt ist. Die Hilfsgrösse $\mathrm{y}_{3}$ bedeutet die Carrying capacity im Sinne von Volterra [44] und Lotka und entspricht etwa dem Futterangebot. Im übrigen wird angenommen, dass alle gestorbenen Bakterien wieder als Futter verwertet werden können. Dies führt zu folgender Gleichung:

$$
\frac{d y_{3}}{d t}=-\frac{d y_{1}}{d t}-\frac{d y_{2}}{d t}+c_{3}\left(y_{1}+y_{2}\right) ; \quad c_{3} \text { in } T g^{-1} .
$$

Die Konstante $c_{3}$ bedeutet den irreversiblen Verlust aus dem System. Wenn alle Variablen in Bakterienkonzentrationen eingesetzt werden, fallen alle sonst üblichen Umwandlungsfaktoren bzw. «Ausbeuten» weg.

Die Identifikation der Parameter (d.h. die Ermittlung der Zahlenwerte der Konstanten $c_{1}, c_{2}, c_{3}$ ) bot einige Schwierigkeiten. Die Konstante $c_{3}$ stammt aus Kapitel 5.2. Die beiden andern Konstanten wurden graphisch ermittelt und sind mit relativ grossen Fehlern behaftet.

Tabelle 12. Startbedingungen und Konstanten für die Simulationen.

\begin{tabular}{|c|c|c|c|c|c|c|c|c|}
\hline $\mathrm{Nr}$. & $\mathrm{y}_{10} / \mathrm{gGV}$ & $\mathrm{y}_{20} / \mathrm{gGV}$ & $\mathrm{y}_{30} / \mathrm{gGV}$ & $\mathrm{y}_{10}+\mathrm{y}_{20} / \mathrm{gGV}$ & $c_{1} / \mathrm{Tg}$ & $c_{2} / \mathrm{Tg}$ & $c_{3} / \mathrm{Tg}$ & $G(\%)$ \\
\hline 1 & $5,95 \mathrm{E} 10$ & $8,90 \mathrm{E} 9$ & 8,90 E9 & $6,84 \mathrm{E} 10$ & 0,99 & 0,200 & 0,013 & 87 \\
\hline 2 & $5,70 \mathrm{E} 10$ & 9,91 E9 & $8,91 \mathrm{E} 9$ & $6,60 \mathrm{E} 10$ & 0,60 & 0,154 & 0,013 & 86 \\
\hline $3 a$ & 4,40 E9 & $4,40 \mathrm{E} 9$ & 5,62 E 10 & 8,81 E9 & 0,06 & 0,139 & 0,013 & 50 \\
\hline $3 b$ & 1 & 8,81 E9 & 5,62 E10 & $8,81 \mathrm{E9}$ & 0 & 0,075 & 0,013 & 0 \\
\hline 4 & $1,49 \mathrm{E} 10$ & $8,91 \mathrm{E} 9$ & 6,4 E10 & $2,38 \mathrm{E} 10$ & 0,32 & 0,15 & 0,013 & 62 \\
\hline
\end{tabular}

Table 12. Initial values and constants for simulation (cf. fig.11).

Die Zahlen der Bakterienkonzentrationen beziehen sich auf die direktgezählten Bakterien/g Gluhverlust; Kolonnenbezeichnungen siehe Text.

G (in Tab. 12) wurde berechnet als $y_{1} /\left(y_{1}+y_{2}\right) \times 100$ und ist der prozentuale Anteil der Gesamtpopulation, welcher vergiftet wird. Wie aus den beiden Ansätzen für Versuch $3 \mathrm{zu}$ sehen ist, können verschiedene Konstanten zusammen mit verschiedenen Anfangsbedingungen zur gleichen Summenkurve führen. Der Ansatz 3a nimmt an, dass die Hälfte der vorhandenen Bakterien nicht von den angebotenen Algen leben kann und verhungert oder sonstwie eliminiert wird. Diese Annahme, so unglaublich sie ist, führt zu einer mehr oder weniger vernünftigen Wachstumsrate. Die simulierten Kurven sind in der Abb.10.3a dargestellt. In Abb. 10.2 (Versuch 2, geringe Heizölbelastung) fällt auf, dass sich die gemessenen Punkte nur dann angleichen liessen, wenn eine lag-Zeit von etwa 3 Tagen an- 

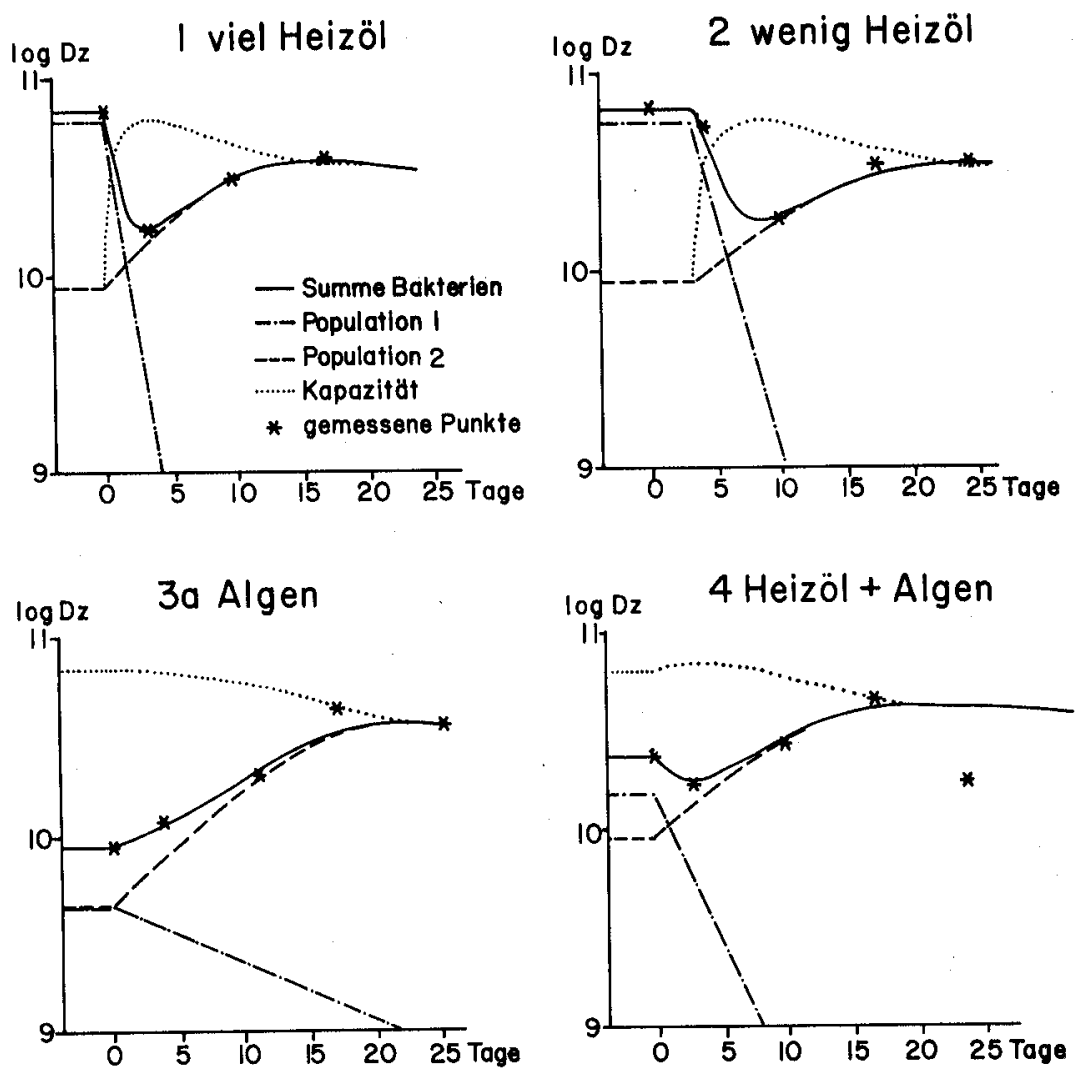

Abb. 10. Simulation der Versuchsverläufe.

Figure 10. Simulation of time curves of direct counted bacteria splitted in two populations. The first dies only and the second one develops on the dead of the first population and on the pertubating substance.

genommen wurde. Dies bedeutet, dass sich eine geringe Konzentration erst nach einer gewissen Zeit auswirkt. Mit dieser Art der Analyse lassen sich Vergiftungen von weniger als der Hälfte der Gesamtpopulation nicht nachweisen. Wenn man die Werte von $G$ mit den einfacher ermittelten Vergiftungsanteilen in Kapitel 4 vergleicht, führte die Simulation immer zu grösseren Anteilen.

\subsection{Neubesiedelungstheorie und Stabilität}

Die Gesamtheit des Angebots von abbaubaren Substanzen kann als ein Informationsangebot der Umwelt $\left(\mathrm{I}_{\mathrm{U}}\right)$ für die Biozönose verstanden werden. Von einem Klon eines Lebewesens wird angenommen, dass alle Mitglieder dieselbe Informationsmenge $I_{A}$ besitzen, welche nach Jernelöv [20] aus sämtlichen apparenten und stimulierbaren Eigenschaften besteht. (Die Basensequenz der DNS und die Somaeigenschaften wären eine Möglichkeit, dieses $\mathrm{I}_{\mathrm{A}}$ auszudrücken. In der Praxis muss man sich allerdings mit einer Teilmenge von $I_{A}$ begnügen.) Das Informations- 
gebiet der Konkurrenz ist gleich der Schnittmenge von $\mathrm{I}_{\mathrm{Ai}}$ mit $\mathrm{I}_{\mathrm{Aj}}$ (wobei Ai den $\mathrm{i}$-ten und Aj den $\mathrm{j}$-ten Klon bedeuten), woraus sich auch der Selektionsdruck beschränkt. Als Formel ${ }^{3}$ ):

Selektionsdruck: $\quad I_{\mathrm{Ai}} \cap \mathbf{I}_{\mathrm{Aj}}$.

Bei der Neubesiedelung eines Biotops ist die Information der Umwelt grösser als die Vereinigung der Information der Lebewesen:

$$
\mathrm{I}_{\mathrm{U}}>\cup \mathrm{I}_{\mathrm{A}} \text {. }
$$

Später steigt die Artenzahl, und damit wird die Schnittmenge an Information zwischen zwei Organismen grösser als Null:

$$
\cap \mathrm{I}_{\mathrm{A}}>0 \text {. }
$$

Erst in diesem Stadium einer Besiedelung kann es also zu Interaktionen kommen, und damit beginnt der Selektionsdruck auf die einzelnen Organismen. Weiterhin kann postuliert werden, dass nie die gesamte Informationsmenge eines Lebewesens eine Teilmenge der Information eines andern Lebewesens sein kann, sonst stirbt jenes aus:

$$
\left(\mathrm{I}_{\mathrm{U}} \cap \mathrm{I}_{\mathrm{Aj}}\right) \not \subset\left(\mathrm{I}_{\mathrm{U}} \cap \mathrm{I}_{\mathrm{Ai}}\right) .
$$

Bei einer Weiterentwicklung der Gesellschaft werden die einzelnen $I_{A}$ kleiner, da die Schnittmengen bzw. Konkurrenzgebiete der Arten gegen Null gehen:

$$
\mathrm{I}_{\mathrm{Ai}} \cap \mathrm{I}_{\mathrm{Aj}} \rightarrow 0 .
$$

In diesem Stadium ist es denkbar, dass bei einem Artverlust die Vereinigung der Information der Lebewesen nur noch eine Teilmenge des Informationsangebots der Umwelt wird.

$$
\cup \mathrm{I}_{\mathrm{A}} \subset \mathrm{I}_{\mathrm{U}} \text {. }
$$

Die Klimax, das Endstadium der Entwicklung einer Biozönose, hat die Zielfunktion: Die Vereinigung der Information der Lebewesen deckt exakt das Informationsangebot der Umwelt ab, d.h. die Bedingung geht von

$$
\left(\cup \mathrm{I}_{\mathrm{A}}<\mathrm{I}_{U}\right) \rightarrow \rightarrow \cup \mathrm{I}_{\mathrm{A}} \gg \mathrm{I}_{U} \quad \mathrm{zu} \quad \cup \mathrm{I}_{\mathrm{A}}=\mathrm{I}_{\mathrm{U}},
$$

was gleichbedeutend ist mit:

$$
\neg \mathrm{I}_{\mathrm{U}} \cap \mathrm{I}_{\mathrm{A}} \rightarrow 0 \text { und } \sum \mathrm{I}_{\mathrm{Ai}} \cap \mathrm{I}_{\mathrm{Aj}} \rightarrow 0,
$$

d.h. es wird postuliert, dass überflüssige Information hemmend wirkt.

3) Symbole: $A \cap B$ Schnittmenge von $A$ mit $B ; A \cup B$ Vereinigung von $A$ und $B ; A \in B$ A ist eine Teilmenge von $B ; A \nsubseteq B$ A ist keine Teilmenge von $B ; \neg$ Nicht. 
Dieses Modell bezieht sich nur auf die Wechselwirkungen einer einzigen trophischen Stufe. Jede trophische Stufe liefert ihr $\mathrm{I}_{U}$ für die nächsthöhere. Da sich aber ein Ökosystem selten in unterscheidbare Stufen unterteilen lässt, sondern meist aus einer netzartigen Verknüpfung der Wechselwirkungen der Organismen besteht, müsste für jeden zusätzlichen Klon ein Beitrag für das $\mathrm{I}_{U}$ angenommen werden.

Stabilität:

Die Stabilität eines Ökosystems ist gross, wenn sich die «Arten»-Zusammensetzung nach einer Belastung der Biozönose nicht oder nur wenig ändert $[17,20,28]$. Dies heisst: Eine Veränderung von $\mathrm{I}_{U}$ erzeugt im stabilen System keine Veränderung von $I_{A}$. Das kann erreicht werden, wenn die Vereinigung der Information der Organismen sowie die Summe der Information maximal sind:

Maximale Information: $\cup I_{A}$ und $\sum I_{A} \rightarrow$ maximal.

Veränderungen von $I_{U}$, seien es Verkleinerungen oder Verschiebungen, können vom Ökosystem nur dann aufgefangen werden, wenn keine Art mit ihrer Information ausserhalb des Informationsangebots der Umwelt fällt:

Stabilitätsbedingung: $\mathrm{I}_{\mathrm{Ai}} \not \subset\left(\neg \mathrm{I}_{\mathrm{U}}\right)$.

Das kann nur in einem Entwicklungsstadium des Ökosystems sein, wo $I_{A i} \cap I_{A j}$ gross ist, d.h. in der Zeitspanne der maximalen Information der Biozönose. In Analogie gilt hier (mit Stumm, im Gegensatz zu Pielou [38, 32]), dass maximale Information (und nicht maximale Artendiversität) maximale Stabilität bedingt [siehe auch die Gleichung (18) für Klimax].

Für die durchgeführten Versuche bietet die Zufuhr von Heizöl, in $\mathrm{I}_{U}$ ausgedrückt, folgendes Bild: Die Schnittmenge der Umweltinformation vorher mit der Informationsmenge, welche nicht die Umweltinformation nachher ist, entspricht der Menge der Giftwirkung.

$$
\text { Gift: } \quad \mathbf{I}_{\mathbf{U}_{\text {vorher }}} \cap\left(\neg \mathrm{I}_{\mathrm{U}_{\text {nachher }}}\right)
$$

(«verlorene Information»).

Die neue Information entspricht dem zusätzlichen Informationsangebot durch Kohlenwasserstoffe:

$$
\text { Neue Information: }\left(\neg \mathrm{I}_{\mathrm{U}_{\text {vorher }}}\right) \cap \mathrm{I}_{\mathrm{U}_{\text {nachher }}} \text {. }
$$

Bei kleinen Zugaben von Heizöl ist die Umweltinformation vor der Zugabe eine wahre Teilmenge der Umweltinformation nachher; d.h. keine Vergiftung, da die Zugabemenge zu klein ist.

Für den Übergang und die Anwendung auf die erhobenen Daten sind folgende weitere Annahmen notwendig:

Als Einheitsmenge wird die Information eines (jedes) taxonomischen Merkmals betrachtet. 


$$
1=\mathbf{I}_{\mathbf{T k}}
$$

wobei $\mathbf{I}_{\mathbf{T}}$ die Information eines taxonomischen Merkmals und $\mathrm{k}$ die Laufzahl bedeute.

Die Stabilität wird maximal, wenn die Summe der Schnittmengen der Information der Bakterien oder eventuell wenn die Summe der Schnittmengen der Information der Bakterien mit der Informationsmenge, welche die Umwelt momentan nicht anbietet, maximal wird:

$$
\text { Stabilitätsmaximum: } \sum_{\rightarrow \text { maximal }} I_{A i} \cap I_{A j} \text { oder } \sum_{\rightarrow \text { maximal }} I_{A i} \cap\left(\neg I_{U}\right) \text {, }
$$

d.h. dass eine grosse Menge «überflüssiger» Antworten auf (noch) nicht existierende Fragen vorhanden sind.

Die Ähnlichkeit von zwei Bakterienstämmen ist gleich dem Durchschnitt der Information dieser beiden:

$$
\mathbf{I}_{\mathrm{Ai}} \cap \mathbf{I}_{\mathrm{Aj}}
$$

$\mathrm{Da}$ die Information eines taxonomischen Merkmals ein Element der Information eines Bakterienstammes ist (oder eventuell auch eine Teilmenge, wenn die Information des taxonomischen Merkmals nicht als Einheitsmenge, sondern als Ausdruck noch tieferer Informationsstufen betrachtet wird) bzw. $\mathrm{I}_{\mathrm{Tk}} \in \mathrm{I}_{\mathrm{Ai}}$ oder evtl. $\mathrm{I}_{\mathrm{Tk}} \subset \mathrm{I}_{\mathrm{Ai}}$, wenn $\mathrm{I}_{\mathrm{Tk}} \neq 1$, so wird die Ähnlichkeit gleich der Summe der Durchschnitte der Information der taxonomischen Merkmale:

$$
\text { Ähnlichkeit: } \sum\left(\mathbf{I}_{\mathbf{T k}} \cap \mathbf{I}_{\mathrm{T} \mathbf{1}}\right) \text {, }
$$

was dem einfachen «match index» entspricht; d.h. diese Formel bedeutet nichts anderes als

$$
\ddot{A} \text { Anlichkeit }=\frac{\text { Anzahl gleicher Merkmale }}{\text { Anzahl verglichener Merkmale }},
$$

wie sie auch in Kapitel 3.42 erscheint [Gleichung (1)].

\subsection{Informationssummen der Versuche}

Die Informationssumme eines Versuchs wurde nach Williams et al. [48] ausgerechnet (vgl. 3.43).

Die Informationen wurden auf 100 Stämme normiert mit Hilfe folgender Formel:

$$
I_{100}=\frac{I_{N} \cdot 100^{3 / 2}}{N^{3 / 2}}
$$

$\mathrm{N}=$ Zahl der Bakterienstämme.

Die Additivität der Informationen ist also über eine stetige Funktion verzerrt. 


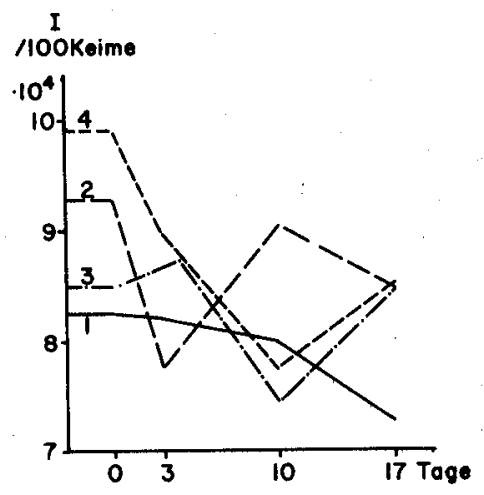

Abb. 11. Normalisierte Information der Bakterienpopulationen auf 100 Keime.

Figure 11. Information of populations of bacteria normalized on 100 germs.

In Abb. 11 sind die Informationsverläufe der vier Versuche dargestellt. Es fällt auf, dass in allen Versuchen mit Öl bei Versuchsbeginn ein Informationsverlust auftritt, der aber mit Ausnahme von Versuch 1. $\left(1 \mathrm{~g} \mathrm{Heizöl} / \mathrm{dm}^{2}\right)$ reversibel ist (Stabilitätsbedingung nach Imboden [17] erfüllt). Theoretisch würde man erwarten, dass die Information (oder Diversität im Jernelövschen Sinn [20]) der Bakterienpopulation durch ein zusätzliches Angebot von Kohlenwasserstoffen gesteigert wird. Dies ist jedoch nur bei den Versuchen 2 und 4 der Fall (bei gleichzeitiger Berücksichtigung der möglichen Fehler dieser Information). Im Versuch 3 wurden Chlorellen zugegeben, d.h. die Zugabe bewegte sich im Rahmen des natürlichen Angebots des Sees an die Bakterienflora des Seesediments (keine ökosystemfremden Verbindungen). Dementsprechend blieb auch die Information der Bakterien von Versuchsbeginn bis Versuchsende innerhalb des Fehlers konstant.

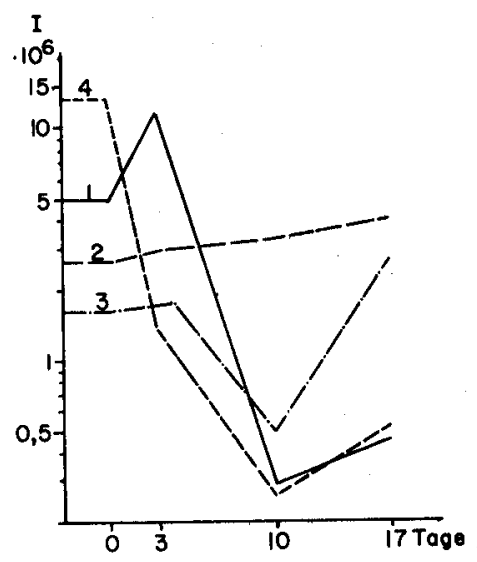

Abb. 12. Information bezüglich der Direktzah1 bzw. pro mg Trockensubstanz des Sediments.

Figure 12. Information based on direct count and $\mathrm{mg}$ dry substance of sediment. 
Wenn man annimmt, dass pro nicht kultivierbares Bakterium dieselbe Informationsmenge vorhanden ist wie pro kultivierbares, so kommt man zu der in Abb. 12 dargestellten Beziehung:

Die Information in Versuch 1 (viel öl) steigt wenig an und geht anschliessend weitgehend verloren. Offenbar spielt bei dieser Konzentration des Öls dessen Giftigkeit eine grössere Rolle als die Verwertbarkeit. Bei längerer Laufzeit des Experimentes wäre auch der umgekehrte Fall denkbar.

Wie schon in Abb.11 gezeigt, bleibt die Information des Versuchs 3 über die ganze Zeit etwa konstant (innerhalb der Fehlergrenzen).

Bei dieser Darstellung zeigt hingegen der Versuch 4 typische Vergiftungserscheinungen, was für eine negative Wechselwirkung zwischen Algen und Heizöl sprechen würde (vgl. auch 5.2).

\section{Versuch einer Extrapolation der Bakterienversuche auf Seen}

\subsection{Kohlenwasserstoffeintrag Bodensee}

Unger bestimmte 1970 in den obersten $3 \mathrm{~cm}$ des Bodenseesediments Kohlenwasserstoffe [42]. Aus diesen Analysenwerten lassen sich für den ganzen See etwa $1300 \mathrm{t}$ hochrechnen. Nach Züllig [51] entsprechen diese $3 \mathrm{~cm}$ der Sedimentation von 6 bis 10 Jahren, daraus folgt ein Jahreseintrag von 130 bis $220 \mathrm{t}$ für die Sedimente. Höchstkonzentrationen sind nach Unger in $30 \mathrm{~m}$ Seetiefe, etwa $600 \mathrm{~m}$ vor Flussmündungen, zu finden und betragen bis $0,6 \mathrm{~g} \mathrm{KW}$ pro $\mathrm{kg} \mathrm{Naßsediment.}$

Die KW-Fracht kann auf folgende Quellen verteilt werden: Ölunfälle: In der Periode 1976/77 wurden folgende Mengen registriert: 1,5 t Heizöl, 3,9 t Kerosin und 0,2 t Getriebeöl. Zusätzliche Unfälle lieferten 11,5 t Heizöl und 2,5 $\mathrm{t}$ Dieseltreibstoff [18].

Motorboote: Nach einem Industrie-Gutachten 1973 [11] gaben die Motorboote etwa 18 t Zweitakt- und andere Schmieröle in den See. Nach einer Extrapolation von Zahner (mündl. Mitt. 1974) beträgt der Wert für 197727 t/Jahr. Aus einem internen Bericht der Bodenseekommission (1973) stammen folgende Zahlen:

Motorbootöleintrag:

$\begin{array}{llcl}\text { Total } & \text { Fraktion } & \text { Zufuhr ins } & \text { Verlust durch } \\ & & \text { Freiwasser } & \text { Verdampfen, Abbau } \\ 21 \mathrm{t} & & 6 \mathrm{t} & -70 \% \\ \text { «leicht» } & \text { "schwer» } & 15 \mathrm{t} & -40 \%\end{array}$

Diese Zahlen beziehen sich auf Schätzungen der Sommersituation.

Weitere Einträge: Abschwemmung von OOl von Strassen und Kanalisation 200-300 t (vgl. Tab. 13).

Benzineintrag durch Regen und Luft 130-1300 t, welche aber schnell wieder verdampfen, und die autochthon gebildeten Kohlenwasserstoffe. Zusammen können diese übrigen Quellen als die Ergänzung von den ausgewiesenen $47 \mathrm{t}$ Eintrag (27 t Motorboote, $20 \mathrm{t}$ Unfälle), wovon $23 \mathrm{t}$ ins Sediment gehen, auf 130-220 t berechnet werden. Sie geben als Seezufuhr, wenn man die internen Verluste mit $50 \%$ beziffert, 260-440 t pro Jahr, was mit den obigen Schätzungen übereinstimmt. 
Tabelle 13. Vergleich der Öleinträge Bodensee, Zugersee und Extrapolation der Experimente.

Table 13. Oil loading of Lake Constance and Lake Zug with extrapolation of experiments.

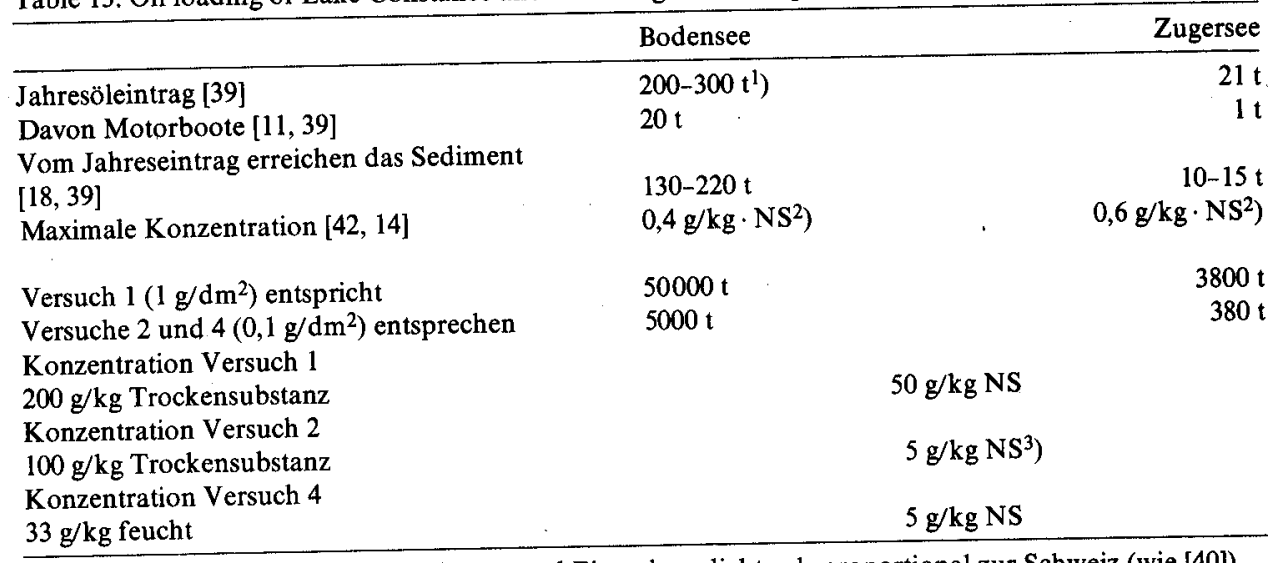

1) Geschätzt aus Einzugsgebiet Bodensee und Einwohnerdichte als proportional zur Schweiz (wie [40]).

2) $\mathrm{NS}=\mathrm{Naßsediment}$.

3) Verteilt auf die obersten $2 \mathrm{~mm}$ des Sedimentkerns.

\subsection{Kohlenwasserstoffeintrag Zugersee}

Als Stellenwert des Öleintrags der Motorboote wurden für 1972 angenommen [39]: 15-20 t Autoöl/Jahr über Zuflüsse, 10-100 t Benzin/Jahr über Luft und $1 \mathrm{t}$ Öl von Motorbooten.

Von diesen Fraktionen verbleiben insgesamt 21 t Öl im See. Davon werden nach Stumm [39] 10-15 t/Jahr ins Sediment eingelagert. Aus Sedimentanalysen [14] lässt sich bei einem Sedimentzuwachs von $1 \mathrm{~mm} / \mathrm{Jahr}$ [51] ein Eintrag von weniger als $23 \mathrm{t}$ / Jahr für das Sediment errechnen, was gut mit den Eintragswerten übereinstimmt. Allerdings ist zu berücksichtigen, dass alle Proben für die Analysen aus der Uferbank erhoben wurden. Nach Literaturbemerkungen [23] dürften im anaeroben Profundalsediment des Zugersees höhere KW-Konzentrationen zu erwarten sein als im Bodensee.

\subsection{Extrapolation der Versuchswerte}

Die Ölbelastungen der Seen werden in Tabelle 13 mit den Belastungswerten dieser Arbeit verglichen. Dabei liegt die höchste Seebelastung rund zehnmal tiefer (Konzentration) als die niedrigste Belastung im Experiment (Versuche 2 und 4). Wie in Kapitel 4 beschrieben, waren in diesen Versuchen kaum Vergiftungserscheinungen bei der Bakterienpopulation zu beobachten. Zufällig anwesende Tubifiziden überlebten auch im höher belasteten Sedimentkern $\left(1 \mathrm{~g} \mathrm{O} \mathrm{V} / \mathrm{dm}^{2}\right.$, Versuch 1).

Diese Beobachtung hat als Toxizitätstest geringe Relevanz, da die Würmer in tiefere Schichten mit geringeren Konzentrationen ausweichen konnten; dasselbe dürfte aber auch im See nach einem Ölunfall möglich sein. Veränderungen der Bakterienpopulation wären demnach etwa bei einem Eintrag von $5000 \mathrm{t}$ Heizöl 
pro Bodensee bzw. $400 \mathrm{t}$ pro Zugersee und Jahr zu erwarten (5000 mal 2 wegen Abbau und Verlust und wiederum dividiert durch $2^{4}$ ) wegen der Unregelmässigkeit der Flächenverteilung), somit beim 20fachen Wert (Fracht) der gegenwärtigen Menge. Die extrapolierten Zahlen enthalten weitere Sicherheit, da die Versuche in Form einer einmaligen Stossbelastung und nicht mit einer Dauerfütterung von Heizöl durchgeführt wurden. Auf der andern Seite darf angenommen werden, dass die gegenwärtige Ölbelastung bereits heute die Bakterienbiozönose gegenüber früher verändert hat. Auf die Oxydation von Kohlenwasserstoffen spezialisierte Organismen können nur dann leben, wenn diese auch dauernd angeboten werden, übrigens eine für die Erdölprospektion verwendete Tatsache (vgl. Kusnetzov et al. [23], Davis [9]). Wie in den Kapiteln 5.4 und 5.5 begründet wurde, steigt die Stabilität der Bakterienbiozönose, wenn eine kleine Ölmenge angeboten wird. Kohlenwasserstoffoxydanten sind beim heutigen dissipativen Verbrauch von Erdöl ubiquitär.

In diesem Zusammenhang noch zwei Zahlen: Der Jahresdurchschnitt 1969/70 der KW-Oxydanten des anaeroben Sediments des mit wenig Öl belasteten Rotsees betrug $22000 / \mathrm{ml} \cdot \mathrm{Naßsediment}$, aber derjenige im aeroben Sediment der Horwer Bucht (die gleiche Stelle wie diese Arbeit) betrug $68000 / \mathrm{ml} \cdot$ Naßsediment. Die Konzentration der KW-Oxydanten ist offenbar nur eine Frage der angebotenen Menge KW und des Sauerstoffs. (Im übrigen ist auch eine anaerobe Zersetzung von $\mathrm{KW}$ bekannt [23].)

Die obigen Überlegungen gelten ausdrücklich nur für Bakterienbiozönosen. Der Einfluss des Öls auf Invertebraten des Benthos, auf Fischlaich usw. wird hier nicht diskutiert, ebenso nicht die mögliche Anreicherung des Öls in der Nahrungskette.

\section{Zusammenfassung}

Die Wirkungen von Erdöl und Heizöl auf Meereslitoralbiozönosen sind bekannt, dagegen bestehen im Süsswasser wesentliche Wissenslücken. Die seit längerem diskutierte Behauptung, dass Diversität Stabilität impliziert, krankt am Postulat der Artendiversität.

Es wurde experimentell geprüft, wie die Bakterienbiozönose des Sediments der Horwer Bucht (Vierwaldstättersee) auf eine Störung durch Heizöl reagiert.

Die Bakterienpopulation wurde während 17 Tagen mit Hilfe folgender Methoden charakterisiert: Single link clustering, einem «centroid clustering»-Programm (welches Art- bzw. Gattungsnamen zuweist), Informationssummen, Kurven gleichen Wachstums und Zellzahlbestimmungen (Direktzahl oder Kultivierung auf Pepton-Glucose-Agar). Der Einsatz der Methoden wurde mit Hilfe der Netzplantechnik optimiert.

Bei Zugabe von $1 \mathrm{~g} \mathrm{Heizöl} / \mathrm{dm}^{2}$. Sediment erfolgte ein langsamer Zusammenbruch des Ökosystems, dessen Erholung während der Versuchsdauer von 17 Tagen nicht beobachtet werden konnte. Die Informationssumme und auch alle Messgrössen wurden kleiner.

Bei einer Zugabe von $0,1 \mathrm{~g}$ Heizöl/ $/ \mathrm{dm}^{2}$. Sediment vergrösserte sich die Informa-

4) Dieser Divisor wird für Uferbereiche überschritten. 
tionssumme, welche als ein Mass für die Stabilität betrachtet werden kann. Zugleich wurden aber, gemessen an der Direktzahl und modellmässig hochgerechnet, $80 \%$ der Zellen vergiftet.

Auf Störung der ausgehungerten Population in Form einer Zugabe von Algen (Chlorella) reagierten die Bakterien nur mit einer höheren Zellzahl. Die Informationssummen und die Kurven gleichen Wachstums bezüglich der Temperatur blieben gleich. Bei einer gleichzeitigen Zugabe von Algen (Chlorella) und $0,1 \mathrm{~g}$ Heizöl $/ \mathrm{dm}^{2}$. Sediment wird ein Vergiftungseffekt sichtbar, welcher, gemessen an der Direktzahl und modellmässig hochgerechnet, $60 \%$ der Zellen betrifft. Später wurde er gefolgt von einem Anstieg der Keimzahl. Die Informationssumme nahm während des ganzen Versuchs ab, ein Indiz dafür, dass Heizöl auf eine gutgenährte Bakterienpopulation einen schädlicheren Einfluss hat als auf Hungerformen. Das Postulat, dass sedimentierte Algenzellen und Heizöl (mindestens aerob) gleichzeitig abgebaut werden, konnte bestätigt werden.

Eine Extrapolation der Versuchsergebnisse auf den Bodensee führt zum Schluss, dass die Ölbelastung rund $5000 \mathrm{t} / \mathrm{Jahr}$ (tatsächliche Belastung 1976 etwa $200 \mathrm{t}$ ) betragen muss, um die Bakterienbiozönose nachweisbar zu verändern. Für den Zugersee sind ähnliche Verhältnisse wahrscheinlich (berechnet: $380 \mathrm{t}$ gegenüber einer 1972 gemessenen Belastung von etwa $21 \mathrm{t}$ ).

\section{SUMMARY}

Influence of hydrocarbons on ecology of bacteria in aerobic lake sediment

Many toxic actions are known to be caused by fuel and crude oil to biocoenosis of seashore. We have far less experience in lakes. Bacteria biocoenosis in sediment cores of Lake Lucerne was pursued after addition of fuel oil. Biocoenosis was characterized by following methods: Single link clustering, a centroid clustering which gives estimates of names, sums of information, isoauxates (i.e. curves of even growth) and cell counts. Application and sequence of methods were optimized by net plan technique. A loading of $100 \mathrm{~g}$ fuel $\mathrm{oil} / \mathrm{m}^{2}$. sediment caused a partial destruction of ecosystem. Full restoration could not be observed. When $10 \mathrm{~g} / \mathrm{m}^{2}$ were applied there was no significant effect. When the starved population was fed on algae (Chlorella pyrenoidosa) the only reaction was an increase of cell count. Sum of information and isoauxates remained as on start. As shown in a separate chapter sum of information of a mature ecosystem should change only if information of ecosystem (e.g. physical forcing functions or in this example a different contribution of organic substances) changes too. Addition of algae is only a quantitative but not a qualitative change. Therefore it is sensible that neither stability nor sum of information shows a difference. When $10 \mathrm{~g}$ fuel and $200 \mathrm{~g}$ algae were supplied together, the effect was similar to $100 \mathrm{~g}$ fuel. Theory that sedimented algae and fuel oil are decomposed at the same time could be confirmed. An extrapolation of the results gives a tolerance of hydrocarbon loading for the Lake Constance or Lake Zug of 10 to 20 times the load present. Effects on fishes or fishfood were not considered.

\section{RESUME}

L'influence d'hydrocarbures sur l'écologie des bactéries dans le sédiment aérobe

Des carottes de sédiments du lac de Lucerne étaient traitées avec deux quantités d'huile combustible et examinées 4 fois pendant 21 jours. Les méthodes utilisées étaient: Comptage directe, isolation d'une centaine de colonies sur peptone glucose agar dilué, détermination de 42 attributs (à 282 marches), suivie par une cluster analyse et le calcul d'une somme d'information qui est basée sur les attributs (c.-à-d. une mesure pour l'entropie négative). L'addition de $100 \mathrm{~g}$ combustible $/ \mathrm{m}^{2} \mathrm{de}$ sédiment abaissait et le nombre des germes et la somme d'information. Avec $10 \mathrm{~g} / \mathrm{m}^{2}$ les effets 
n'étaient pas significatifs, ce qui changeait après l'addition supplémentaire d'algues. Avec algues et sans huile le seul effet était l'augmentation du nombre des germes sans changement de la somme d'information. L'extrapolation des résultats donne une tolérance des bactéries de 10 à 20 fois la quantité actuelle pour le lac de Zoug ou le lac de Constance. (Cette tolérance se comprend sans tenir compte des effets toxiques pour les poissons, etc.)

\section{VERDANKUNG}

Besonderer Dank gebührt Herrn Prof. Dr. H. Ambühl für die Ubberarbeitung des Manuskripts sowie für seine stets bewiesene Geduld. Den Diskussionen zu «Zielsetzungen des Gewässerschutzes» mit Prof. Dr. W. Stumm sowie Prof. Dr. R. Margalef und Herm A.B. Jernelöv verdanke ich den Ansatz zu dieser Arbeit.

Meinen Kollegen U. Uehlinger und H.J. Fricker sowie Dr. D. Imboden danke ich fur manch fruchtbare Diskussion, ferner Dr. J. Bloesch für die kritische Durchsicht des Manuskripts.

Mein Dank gilt ferner Frl. H. Bolliger für Reinzeichnungen, den Herren Schlup und Isler für photographische Arbeiten und Frl. T. Oberholzer für Schreibarbeiten.

Diese Arbeit wurde zu Beginn mit Unterstützung der «Stiftung der Wirtschaft zur Förderung des Gewässerschutzes in der Schweiz» durchgeführt.

\section{LITERATURVERZEICHNIS}

1 Ambühl, H., und Bührer, H.: Zur Technik der Entnahme ungestörter Grossproben von Seesediment; ein verbessertes Bohrlot. Schweiz. Z. Hydrol. 37, 175-186 (1975).

2 BBL-Manual of Products and Laboratory Procedures, 5. Aufl. (1968).

3 Beerstecher, E., Jr.: Petroleum Microbiology. Elsevier, Houston, New York 1954.

4. Bloesch, J.: Sedimentation und Phosphorhaushalt im Vierwaldstättersee (Hower Bucht) und im Rotsee. Schweiz. Z. Hydrol. 36, 71-186 (1974).

5 Breed, R.S., Murray, E.G., und Parker, A.: Hitchens Eds. of Bergey's Manual of Determinative Bacteriology, 6.Aufl., 1529 S. (1948).

6 Buchanan, R.E., und Gibbons, N.E., et al. (Hrsg.): Bergey's Manual of Determinative Bacteriology, 8.Auf1., 1268 S. (1975).

7 Bührer, H.: Modifizierte Acidinorange-Färbemethode für die Direktzăhlung von Sedimentbakterien. Schweiz. Z. Hydrol. 39, 99-103 (1977).

8 Davis, F.: Symposium on Petroleum Microbiology. Bact. Rev. 20, 261 (1959).

9 Davis, J.B.: Petroleum Microbiology, 604 S. Elsevier, Amsterdam 1967.

10 Denbigh, K.: The Principles of Chemical Equilibrium. University Press, Cambridge, England, 1955.

11 Dornier: Gutachten über den Öleintrag der Motorboote in den Bodensee (1973), verfasst im Auftrag des Landes Baden-Württemberg, zitiert nach [18].

12 Ellenberg, H.: Ziele und Stand der Okosystemforschung. In: Ökosystemforschung, S. 1-31. Springer, Berlin, Heidelberg, New York 1973.

13 Fuhs, G.W.: Der mikrobielle Abbau von Kohlenwasserstoffen. Arch. Mikrobiol. 39, 374-422 (271 Referenzen) (1961).

14 Giger, W., Reinhard, M., Schaffner, C., und Stumm, W.: Petroleum-Derived and Indigenous Hydrocarbons in Recent Sediments of Lake Zug, Switzerland. Envir. Sci. technol. 8, 454-455 (1974).

15 Gunkel, W.: Experimentell-ökologische Untersuchungen über die limitierenden Faktoren des mikrobiellen Ölabbaus im marinen Milieu. Helgoländer wiss. Meeresunters. 15, 210-225 (1967).

16 Hirsch, P.: Stoffwechselphysiologische Untersuchungen an Nocardia petroleophila n.sp. Arch. Mikrobiol. 29, 368-393 (1958).

17 Imboden, D.M.: The Meaning of Stability in Ecology. Unveröffentlicht, Bibliothek EAWAG (1975).

18 Internationale Gewässerschutzkommission für den Bodensee. Akten der Delegiertenkonferenz (1977). 
19 Jardine, N., und Sibson, R.: Mathematical Taxonomy, 286 S. John Wiley \& Sons, London, New York, Sydney, Toronto 1971.

20 Jernelöv, A. B.: Diskussionsbeitrag zum Vortrag von Margalef [28] (1973).

21 Krebs, Ch.J.: Ecology, 694 S. Harper \& Row, New York 1972.

22 Kusnetzov, S.I.: Mikroflora des Wassers, 440 S. Verlag der Wissenschaften, Leningrad 1970.

23 Kusnetzov, S.I., Ivanov, M.V., und Lyalikova, N.N. (C. Oppenheimer und P.T. Broneer): Introduction to Geological Microbiology, 252 S. McGraw-Hill Book Company, New York, San Francisco, Toronto, London 1963.

24 Leifson, E.: Atlas of Bacterial Flagellation. Academic Press, New York, London 1960.

25 Lighthart, B., und Oglesby, R.T.: Bacteriology of an Activated Sludge Treatment Plant - a Guide for Methodology. J. Wat. Pollut. Control Fed. 41, 267-275 (1969).

26 Lockhart, W.R., und Liston, J. (Hrsg.): Methods for Numerical Taxonomy. Bethesda Am. Soc. Microbiol., 62 S. (1970).

27 Margalef, R.: On Certain Unifying Principles in Ecology. Am. Nat. 97, 357-374 (1963).

28 Margalef, R.: External Factors and Ecosystem Stability. Schweiz. Z. Hydrol. 37, 102-117 (1975).

29 Merck, Mikrobiologisches Handbuch (1972), 438 S.

30 Müller, J., und Melchinger, Helga: Methoden der Mikrobiologie, 206 S. Franckhsche Verlagsbuchhandlung, Stuttgart 1964.

31 Pelczar, M.J., et al. (Hrsg.): Manual of Microbiological Methods. Society of American Bacteriologists. McGraw-Hill Book Company, New York 1957.

32 Pielou, E. C.: An Introduction to Mathematical Ecology, 2.Aufl. Wiley Interscience, 1975.

33 Pochon, J., und Tardieux, P.: Techniques d'analyse en microbiologie du sol. Editions de la Tourelle, 1960.

34 Schöberl, P.: Stoffwechselphysiologische Untersuchungen an einem kohlenwasserstoffoxydierenden Pseudomonasstamm aus der Elbe. Arch. Mikrobiol. 56, 354-370 (1967).

35 Schöberl, P.: Zusammenfassungen und Rezensionen über Erdölmikrobiologie. In: Berichte der Botanik (1968ff.).

36 Shannon, C.E.: A Mathematical Theory of Communication. Bell Syst. tech. J. 27, 379-423 (1948) (zitiert nach J.W. MacArthur: Environmental Fluctuations and Species Diversity. In: Ecology and Evolution.) Belknap Press of Harvard University, Massachusetts and London 1975.

37 Sokal, R.R., und Sneath, P.H.A.: Principles of Numeric Taxonomy. Freeman, San Francisco, London 1963.

38 Stumm, W., und Stumm-Zollinger, Elisabeth: Chemische und biologische Modelle als Grundlage zur Beurteilung der Wasserqualităt. Schweiz. Z. Hydrol. 37, 3-20 (1975).

39 Stumm, W., Giger, W., Zobrist, J., und Reinhard, M.: Die Gewässerbeeinträchtigung durch motorisierten Bootsbetrieb auf dem Zugersee und dem Ägerisee. EAWAG-Gutachten im Auftrag des Kantons Zug (1972).

40 Stumm, W., und Thüer, M.: Der Beitrag des Autos zur Gewässerverschmutzung. Quellen, Anteile und Auswirkungen. Mensch-Auto-Umwelt (Vortrag 16.Tagung ACS) (1973).

41 Thüer, M.: Transportmechanismen von $O \mathrm{O}$ in natürlichen Gewässern unter besonderer Berücksichtigung von Sedimentations- und Flotationsbedingungen bei der Heterokoagulation von kolioidalen Oltröpfchen mit mineralischen Schwebstoffen. Diss. ETH, Nr. 5628, 1975.

42 Unger, U.: Untersuchungen über die Verunreinigung des Bodensees durch Mineralöl. GWF 112, 256-261 (1971).

43 Van der Linden, A.C., und Thijsse, G.J.E.: The Mechanisms of Microbial Oxidations of Petroleum Hydrocarbons. Adv. Enzymol. 27, 469-546 (285 Referenzen) (1965).

44 Volterra, V.: Leçons sur la théorie mathématique de la lutte pour la vie. Gautier-Villars, Paris 1931.

45 Vorosilova, A.A., und Dianova, E.W.: Uber die bakterielle Oxydation des Erdöls und seinen Weg in natürlichen Gewässern. Mikrobiologija 19, 203-210 (1950).

46 Vorošilova, A.A., und Dianova, E.W.: Erdöloxydierende Bakterien als Gradmesser der biologischen Oxydation des Erdöls unter natürlichen Bedingungen. Mikrobiologija 21, 408-415 (1952).

47 Wiener, N.: Cybernetics. MIT Press, Cambridge, Mass., 1948.

48 Williams, W.T., Lambert, J.M., und Lance, G.N.: Multivariate Methods in Plant Ecology V. Similarity Analyses and Information Analysis. J. Ecol. 54, 427-445 (1966). 
49 Wirtz, R.: Zentrbl. Bakt., 1.Abt. 46, 727.

50 Zobell, C. E.: Actions of Microorganisms on Hydrocarbons Review. Bact. Rev. 10, 1-49 (1946).

51 Züllig, H.: Sedimente als Ausdruck des Zustandes eines Gewässers. Schweiz. Z. Hydrol. 18, 5-143 (1956).

Adresse des Autors: Dr. H. Bührer, EAWAG, CH-8600 Dübendorf. 